\title{
Cell-Specific PKM Isoforms Contribute to the Maintenance of Different Forms of Persistent Long-Term Synaptic Plasticity
}

\author{
이iangyuan Hu, ${ }^{1}$ Kerry Adler, ${ }^{1}$ Carole Abi Farah, ${ }^{2}$ Margaret H. Hastings, ${ }^{3}{ }^{\circledR}$ Wayne S. Sossin, $, 2,3$ and Samuel Schacher ${ }^{1}$ \\ 'Department of Neuroscience, Columbia University Medical Center, New York State Psychiatric Institute, New York, New York 10032, ${ }^{2}$ Department of \\ Neurology and Neurosurgery, Montreal Neurological Institute, McGill University, Montreal, Quebec H3A 2B4, Canada, and ${ }^{3}$ Department of Psychology, \\ McGill University, Montreal Neurological Institute, Montreal, Quebec H3A 1B1, Canada
}

Multiple kinase activations contribute to long-term synaptic plasticity, a cellular mechanism mediating long-term memory. The sensorimotor synapse of Aplysia expresses different forms of long-term facilitation (LTF) — nonassociative and associative LTF-that require the timely activation of kinases, including protein kinase C (PKC). It is not known which PKC isoforms in the sensory neuron or motor neuron L7 are required to sustain each form of LTF. We show that different PKMs, the constitutively active isoforms of PKCs generated by calpain cleavage, in the sensory neuron and L7 are required to maintain each form of LTF. Different PKMs or calpain isoforms were blocked by overexpressing specific dominant-negative constructs in either presynaptic or postsynaptic neurons. Blocking either PKM Apl I in L7, or PKM Apl II or PKM Apl III in the sensory neuron $2 \mathrm{~d}$ after 5-hydroxytryptamine (5-HT) treatment reversed persistent nonassociative LTF. In contrast, blocking either PKM Apl II or PKM Apl III in L7, or PKM Apl II in the sensory neuron $2 \mathrm{~d}$ after paired stimuli reversed persistent associative LTF. Blocking either classical calpain or atypical small optic lobe (SOL) calpain $2 \mathrm{~d}$ after 5-HT treatment or paired stimuli did not disrupt the maintenance of persistent LTF. Soon after 5-HT treatment or paired stimuli, however, blocking classical calpain inhibited the expression of persistent associative LTF, while blocking SOL calpain inhibited the expression of persistent nonassociative LTF. Our data suggest that different stimuli activate different calpains that generate specific sets of PKMs in each neuron whose constitutive activities sustain long-term synaptic plasticity.

Key words: Aplysia; calpain; cell culture; long-term facilitation; PKC; PKM

Significance Statement

Persistent synaptic plasticity contributes to the maintenance of long-term memory. Although various kinases such as protein kinase $\mathrm{C}$ (PKC) contribute to the expression of long-term plasticity, little is known about how constitutive activation of specific kinase isoforms sustains long-term plasticity. This study provides evidence that the cell-specific activities of different PKM isoforms generated from PKCs by calpain-mediated cleavage maintain two forms of persistent synaptic plasticity, which are the cellular analogs of two forms of long-term memory. Moreover, we found that the activation of specific calpains depends on the features of the stimuli evoking the different forms of synaptic plasticity. Given the recent controversy over the role of PKM $\zeta$ maintaining memory, these findings are significant in identifying roles of multiple PKMs in the retention of memory.

\section{Introduction}

Persistent changes in synaptic strength contribute to long-term memories (Kandel, 2012; Maren, 2005; Caroni et al., 2012; Col-

Received Sept. 6, 2016; revised Dec. 28, 2016; accepted Jan. 31, 2017.

Author contributions: J.H., W.S.S., and S.S. designed research; J.H., K.A., C.A.F., and M.H.H. performed research; J.H. and S.S. analyzed data; J.H., W.S.S., and S.S. wrote the paper.

The research is supported by National Institutes of Health (NIH) Grant MH-060387 and Canadian Institutes of Health Research Grants MOP 12046 and 340328. Animals were provided by the National Center for Research for Aplysia at the University of Florida in Miami, FL, which is supported by NIH Grant RR-10294.

Correspondence should be addressed to Jiangyuan Hu, Department of Neuroscience, Columbia University Medical Center, New York State Psychiatric Institute, 1051 Riverside Drive, New York, NY 10032. E-mail: jh2004@cumc.columbia.edu. lingridge et al., 2013; Takeuchi et al., 2014; Bailey et al., 2015; Basu and Siegelbaum, 2015). Such changes are mediated by the modulation of gene expression (Abraham et al., 1991; Alberini et al., 1994; Impey et al., 1996; Lanahan and Worley, 1998; Alberini and Kandel, 2014; Veyrac et al., 2014), protein synthesis (Martin et al., 1997a; Sutton and Schuman, 2006; Abraham and Williams, 2008; Costa-Mattioli et al., 2009; Redondo and Morris, 2011; Santini et al., 2014), and kinase activations (Malinow et al., 1988; Lisman, 1994; Thiels and Klann, 2001; Mayford, 2007). Different kinase 
isoforms contribute to the expression of long-term plasticity in the mammalian CNS (Klann et al., 1991; Thomas et al., 1994; Abel et al., 1997; Schafe et al., 1999; Huang et al., 2000; Duffy and Nguyen, 2003; Yang et al., 2004; Nie et al., 2007; Kandel, 2012; Tsokas et al., 2016) and at the sensorimotor synapse of Aplysia (Hegde et al., 1993; Sossin et al., 1994; Martin et al., 1997b; Chain et al., 1999; Purcell et al., 2003; Liu et al., 2004; Fiumara et al., 2015). Despite this wealth of data, little is known about whether coordinated and constitutive activations of specific kinase isoforms in the presynaptic and postsynaptic compartments are needed to sustain long-term plasticity.

The sensorimotor synapse of Aplysia expresses different forms of persistent long-term facilitation (LTF). Nonassociative LTF is produced by repeated applications of serotonin [5hydroxytryptamine (5-HT)] or repeated sensitizing stimuli and is a cellular analog of long-term sensitization (Castellucci et al., 1978; Frost et al., 1985; Montarolo et al., 1986; Cleary et al., 1998; Marinesco et al., 2006; Hu et al., 2011; Hu and Schacher, 2014). Associative LTF is produced by pairing activity in the sensory neuron with 5 -HT or pairing tactile stimulation with sensitizing stimuli, and is a cellular analog of long-term classical conditioning (Carew et al., 1981; Walters and Byrne, 1983; Buonomano and Byrne, 1990; Hu and Schacher, 2015). Each form of LTF requires timely activation of protein kinase A (PKA), MAPK, and PKC (Abrams et al., 1991; Martin et al., 1997a; Chain et al., 1999; Hu et al., 2004, 2006, 2007, 2011; Liu et al., 2004; Shobe et al., 2009; Villareal et al., 2009; Fiumara et al., 2015). Persistent LTF (lasting more than a week) for each form is evoked by two sets of stimuli in 2 consecutive days or after a $5 \mathrm{~h}$ interval, and incubation with the PKC inhibitor chelerythrine resulted in the reversal of nonassociative or associative LTF (Cai et al., 2011; Hu et al., 2011; Hu and Schacher, 2015). Aplysia neurons express the following three isoforms of PKC (Kruger et al., 1991; Bougie et al., 2009): PKC Apl I (classical); PKC Apl II (novel); and PKC Apl III (atypical). Each of these PKC isoforms can be converted to a constitutively active form after calpain-dependent cleavage, PKM Apl I, PKM Apl II, and PKM Apl III, some of which contribute to intermediate forms of facilitation (Sossin, 2007; Sutton et al., 2004; Bougie et al., 2009, 2012; Farah et al., 2016). Which isoforms of PKM in each neuron need to be active to maintain the two forms of persistent LTF?

We manipulated the activity of $\mathrm{PKC} / \mathrm{PKM}$ isoforms or two calpain isoforms, classical and atypical small optic lobe (SOL), using a dominant-negative ( $\mathrm{dn}$ ) approach. We found that cellspecific activations of different PKMs were required to sustain different forms of persistent synaptic plasticity. Calpain activity was not required to maintain persistent LTF, but specific calpain isoform activity was required for the expression of each form of persistent LTF. Thus, different stimuli activate different calpain isoforms that generate specific PKMs in the sensory neurons and L7, whose constitutive activities maintain different forms of long-term plasticity.

\section{Materials and Methods}

Cell culture and electrophysiology. Sensory neurons were isolated from pleural ganglia dissected from adult animals (60-80 g; Aplysia californica, which are hermaphrodites; RRID: SCR_008361), and motor neuron L7s were isolated from juvenile abdominal ganglia $(2 \mathrm{~g})$ and maintained in coculture up to $10 \mathrm{~d}$ ( $\mathrm{Hu}$ et al., 2015). The coculture contained one sensory neuron and one L7. Each culture represented one sample, since each motor neuron L7 was derived from a separate animal. The sensory neurons added to each $\mathrm{L} 7$ for cultures prepared on the same day (between 9 and 13 cultures) were derived from the pleural ganglia of two adult animals (four hemi-ganglia in total). The cultures prepared on the same day were divided into two experimental and two control (Cont) groups for each experiment. Cultures were maintained at $18^{\circ} \mathrm{C}$ and fed every other day with medium containing $50 \%$ filtered hemolymph and $50 \%$ L15.

A standard intracellular recording technique was used to record the amplitude of EPSPs evoked in motor neuron L7. The soma of L7 was impaled with a recording microelectrode $(10-15 \mathrm{M} \Omega)$ filled with a solution containing $2.0 \mathrm{M} \mathrm{K}$-acetate, $0.5 \mathrm{M} \mathrm{KCl}$, and $10 \mathrm{~mm} \mathrm{~K}$-HEPES, pH 7.4. An AxoClamp-2A amplifier and pCLAMP software (Molecular Devices) were used for data acquisition. To accurately record the amplitude of the EPSPs in each coculture, the membrane potential of L7 was hyperpolarized to $-80 \mathrm{mV}$ ( $\sim 25 \mathrm{mV}$ below resting potential), and an EPSP was evoked in L7 by stimulating the sensory neuron with a brief ( $0.3-0.5 \mathrm{~ms})$ depolarizing pulse to evoke an action potential using an extracellular electrode placed near the cell body of the sensory neuron. EPSP amplitudes were monitored before and after various treatments at the indicated time points in the different experiments. The resting potential or input resistance measured in the soma of L7 was not significantly altered by time in culture, stimulation, and/or overexpression of control or experimental constructs. These measures of cell viability changed by $<10 \%$ over the course of the experiments ( $6 \mathrm{~d}$, days $4-10$ in culture). Cultures on day 4 with initial EPSP amplitudes in the range of $15-30 \mathrm{mV}$ were selected ( $85 \%$ of total cultures) for control and experimental conditions. The synaptic strength on day 4 in culture represented the basal synaptic strength (defined as the synaptic baseline), since there was little change in synapse strength over the next week in the absence of stimulation (Hu et al., 2011; Hu and Schacher, 2014, 2015; see Results). The assignment of any culture to control and experimental groups at the start of each experiment on day 4 in culture (defined as day 0 in Results and figures) was to ensure that there were no significant differences in the mean and variance of the initial strength of the synapses between the groups before treatments.

Persistent LTF. Persistent nonassociative LTF lasting more than a week was evoked as reported previously (Hu et al., 2011). After recording the initial EPSP amplitudes of sensorimotor synapses on day 0 , some cultures were exposed to 2 consecutive days (days 0 and 1 ) of 5 applications of 5-HT ( $5 \mu \mathrm{M}$; Sigma-Aldrich) each lasting $5 \mathrm{~min}$ at $20 \mathrm{~min}$ intervals (2 5-HT; see Fig. 1A) to evoke persistent nonassociative LTF. Each application of 5-HT was washed out with a solution containing $50 \%$ seawater and 50\% L15. Control cultures received mock treatments. EPSP amplitudes were re-examined on day 3 ( $2 \mathrm{~d}$ after the last set of applications) before the injections of constructs and at subsequent time points, as indicated in the protocol portion of the figures.

Persistent associative LTF lasting more than a week was evoked by two pairings of a presynaptic tetanus with an application of 5-HT on 2 consecutive days [days 0 and 1; 2 (Tet plus 5-HT); see Fig. 7A], as reported previously (Hu and Schacher, 2015). In brief, after recording the initial EPSP amplitudes on day 0 , the sensory neuron was stimulated with a tetanus $(20 \mathrm{~Hz}$ for $2 \mathrm{~s}$ ) that was followed immediately $(0.5-1.5 \mathrm{~s})$ by an application of 5-HT ( $5 \mu \mathrm{M})$ for $5 \mathrm{~min}$. During the tetanus, motor neuron L7 was maintained at its resting membrane potential $(-55$ to $-60 \mathrm{mV})$. Cultures were rinsed with L15-sea water and then with culture medium (50\% filtered hemolymph and 50\% L15). On day 1, these cultures received a second presynaptic tetanus paired with an application of 5-HT. Control cultures received mock treatments, and in some cultures cells received unpaired stimulation where the application of tetanus and 5-HT were separated by $3-5 \mathrm{~min}$ (unpaired). Two unpaired stimuli evoked no LTF (Hu and Schacher, 2015). The strengths of the synapses were reexamined on day 3 ( $2 \mathrm{~d}$ after the last pairing) and at subsequent time points, as indicated in the protocol portion of the figures.

Plasmid constructs and microinjection. All DNA constructs use the pNEX3 plasmid background and promoter (Kaang, 1996). Dominantnegative monomeric red fluorescent protein (mRFP)-PKMs and dominantnegative mRFP-PKC Apl III have a conserved aspartic acid in the catalytic site converted to alanine (Apl III D392-A, Apl I D444-A, and Apl II D526-A). This mutation removes $>95 \%$ of kinase activity but allows for stabilizing phosphorylation at critical priming sites (Cameron et al., 2009; Bougie et al., 2012; Farah et al., 2016). The dominant-negative mRFP-PKM Apl III and mRFP-PKM Apl I constructs have been shown 

A
Day 0
Day 1
Day 3
Day 4
Day 6
Cont
$\downarrow$ EPSP
2 5-HT

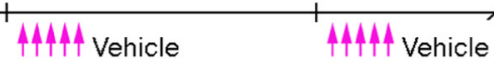
$\downarrow$ EPSP
$\downarrow$ EPSP
$\downarrow$
Injection of constructs
into L7
$\frac{\text { \EPSP }}{444 \uparrow 45 \times 5-H T}$
B
Cont + mRFP
Cont +
dn-PKM Apl I
$\begin{array}{lll}\downarrow \text { EPSP } & \downarrow \text { Injection of constructs } \\ \text { into L7 }\end{array}$
$25-\mathrm{HT}+\mathrm{mRFP}$

\section{$25-\mathrm{HT}+$} dn-PKM Apl I
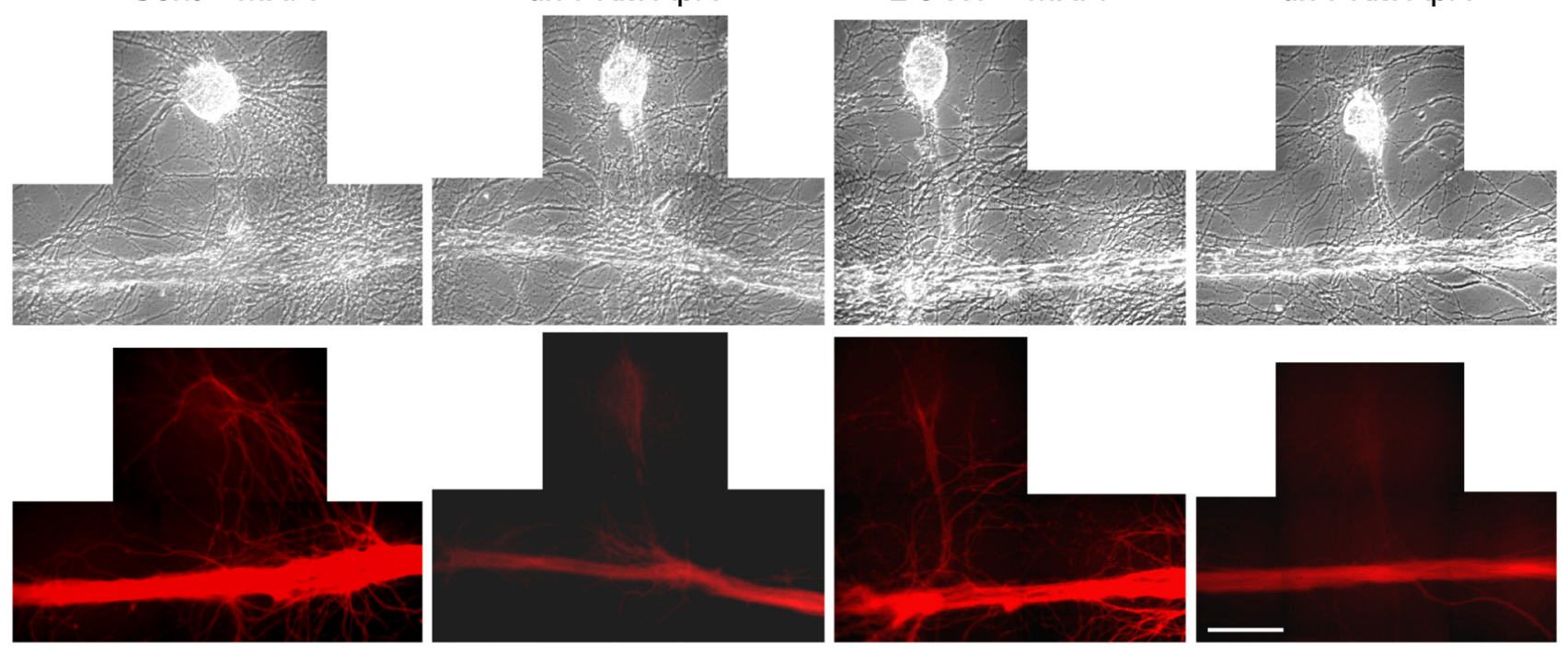

C

Day 0 Day 3

Day 4

Day 6

Cont<smiles>CCCCCCC</smiles>

Cont
+ mRFP<smiles>C1CC2CC12</smiles>

$\overline{-}$

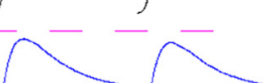

\section{Cont +} dn-PKM Apl I<smiles>C1CCCC1</smiles><smiles>C1CC2CC1C2</smiles>

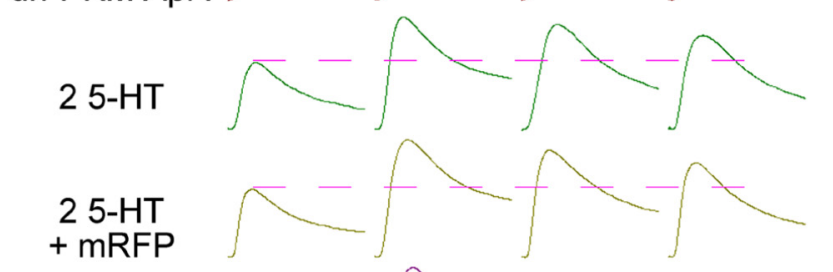

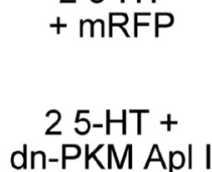<smiles>CCI</smiles><smiles>C1CC2CC1C2</smiles><smiles>CCC1CCCCC1C</smiles>

L7
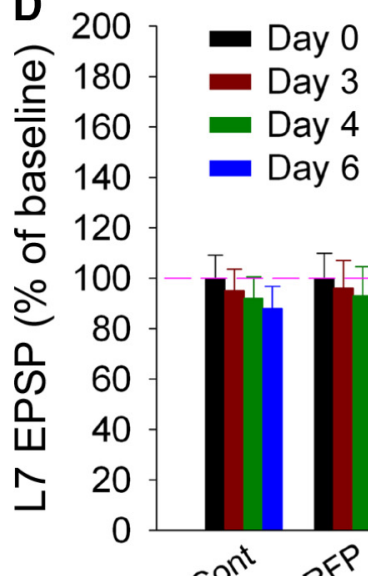

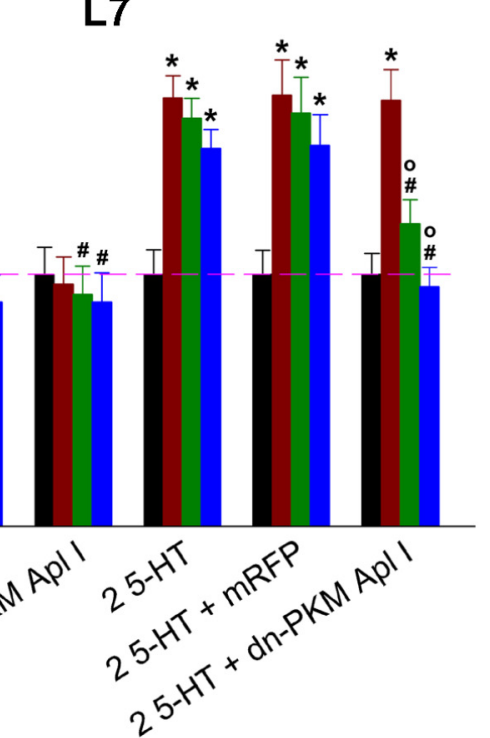

Figure 1. PKM Apll activity in L7 is required after day 3 to maintain persistent nonassociative LTF. A, Experimental protocol for evoking persistent nonassociative LTF consists of repeated applications of 5-HT on days 0 and 1. EPSP amplitudes were tested before control or experimental treatments on day 0 and retested on days 3,4, and 6. Various constructs (control or experimental) were injected into L7 on day 3 . $\boldsymbol{B}$, Phase contrast views of sensorimotor cultures and epifluorescentviews of construct expression in the same view area 24 h after injection. Scale bar, $50 \mu \mathrm{m}$. C, EPSPs in L7 over time for control and experimental groups. Repeated applications of 5-HT resulted in an increase in EPSP amplitude that persisted to day 6, except for the experimental group where L7 overexpressed dn-PKM ApI I (25-HT + dn-PKM Apl I). Overexpression of dn-PKM ApI I did not affect the synaptic baseline in the control group. D, Summary of the changes in EPSP amplitudes for control and experimental groups. A two-factor ANOVA indicated a significant effect of treatment over time $\left(F_{(15,135)}=40.72 ; p<0.001\right)$. Individual comparisons indicated the following: (1) overexpression of dn-PKM Apl I in L7 after control treatment (Cont + dn-PKM Ap I) had no significant effect on the synaptic baseline compared with control or overexpressing mRFP in control $(\#)$ on day $4\left(F_{(5,45)}=0.002\right.$ or $0.001 ;$ all $\left.p>0.8\right)$ and day $6\left(F_{(5,45)}=0.0003\right.$ or $0.0002 ;$ all $\left.p>0.9\right)$; (2) two sets of 5 -HT treatment (25-HT) produced a significant increase in synaptic strength (*) on days 3,4, and 6 compared with Cont, Cont + mRFP, or Cont + dn-PKM Apl I ( $F_{(5,45)}=3.859,3.962$, or 4.649, all $p<0.01$ on day $3 ; F_{(5,45)}=3.981,3.938$, or 3.457 , all $p<0.01$ on day $4 ; F_{(5,45)}=3.923,3.829$, or 3.237 , all $p<0.01$ on day 6$)$; (3) overexpressing control construct mRFP (25-HT + mRFP) on day 3 did not significantly affect the increase in synaptic strength produced by two sets of 5 -HT treatments on days 4 and 6 compared with 25 -HT alone $\left(F_{(5,45)}=0.003\right.$ and $0.002 ;$; all $\left.p>0.9\right)$; (4) overexpressing dn-PKM Apl I on day 3 resulted in a significant reversal of the increase in synaptic strength by $25-\mathrm{HT}\left(25-\mathrm{HT}+\mathrm{dn}-\mathrm{PKM}\right.$ Apl I) on days 4 and 6 (o) compared with other 5 -HT-treated groups $\left(F_{(5,45)}=2.772\right.$ and 3.769 , all $p<0.05$ compared with 25 -HT alone; $F_{(5,45)}=2.946$ and 3.944 , all $p<0.05$ compared with $\left.25-\mathrm{HT}+\mathrm{mRFP}\right)$; and $(5)$ the synaptic strength in 25-HT + dn-PKM Apl I was not significantly different from each control group (\#) on days 4 and $6\left(F_{(5,45)}=0.79\right.$ and 0.069 , all $p>0.5$ compared with Cont; $F_{(5,45)}=0.769$ and 0.056 , all $p>0.5$ compared with Cont + mRFP; $F_{(5,45)}=0.677$ and 0.04 , all $p>0.5$ compared with Cont + dn-PKM Apl I). 


\begin{tabular}{|c|c|c|c|c|c|}
\hline A & $\begin{array}{l}\text { Day } 0 \\
\downarrow \text { EPSP }\end{array}$ & Day 1 & $\begin{array}{l}\text { Day } 3 \\
\downarrow \text { EPSP }\end{array}$ & $\begin{array}{l}\text { Day } 4 \\
\downarrow \text { EPSP }\end{array}$ & $\begin{array}{l}\text { Day } 6 \\
\text { \EPSP }\end{array}$ \\
\hline & $\uparrow \uparrow \uparrow \uparrow \uparrow$ Vehicle & $\uparrow \uparrow \uparrow \uparrow \uparrow$ Vehicle & 4 Inje & & \\
\hline & $\downarrow$ EPSP & & $\downarrow$ EPSP & $\downarrow$ tEPSP & $\downarrow$ EPSP \\
\hline
\end{tabular}

B Cont + dn-PKM Apl II
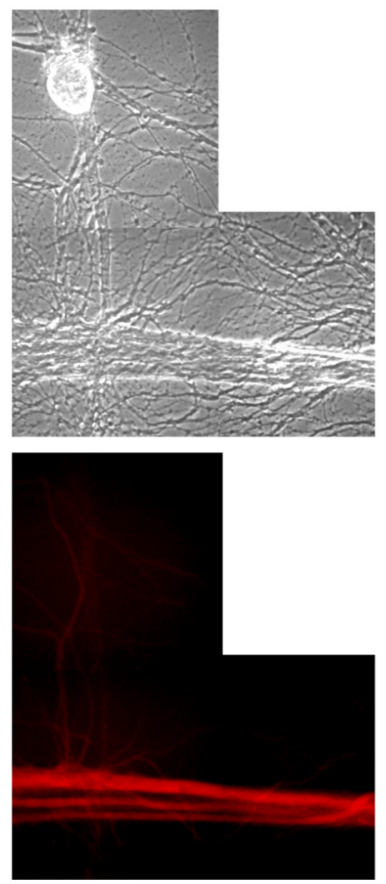

Cont + dn-PKM Apl III
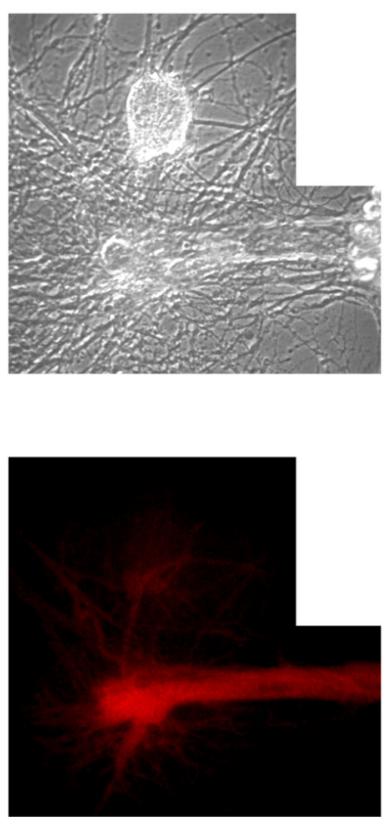

25-HT + dn-PKM Apl II

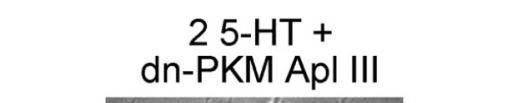

C

Day 0

Day 3

Day 4 Day 6

Cont

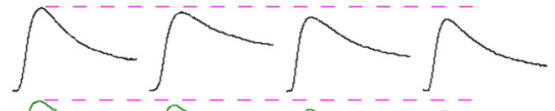

Cont + dn-PKM ApI II
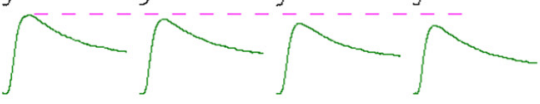

Cont + dn-PKM Apl III
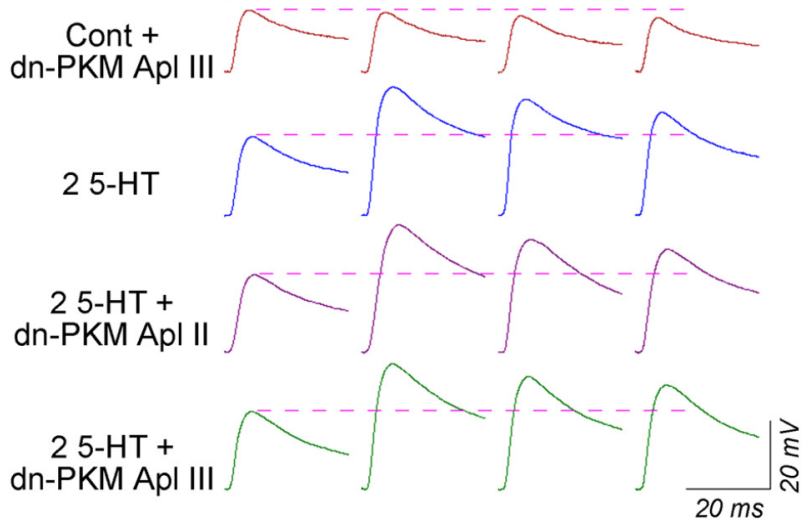
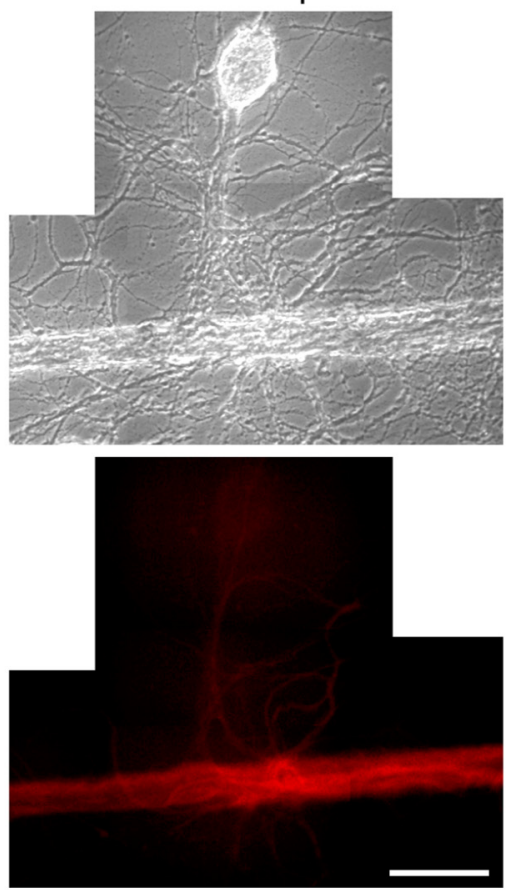
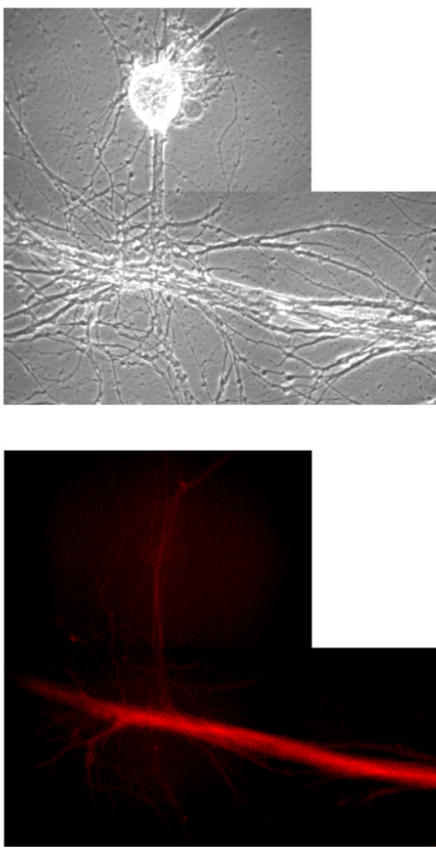

D 200

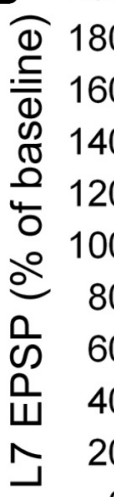

L7
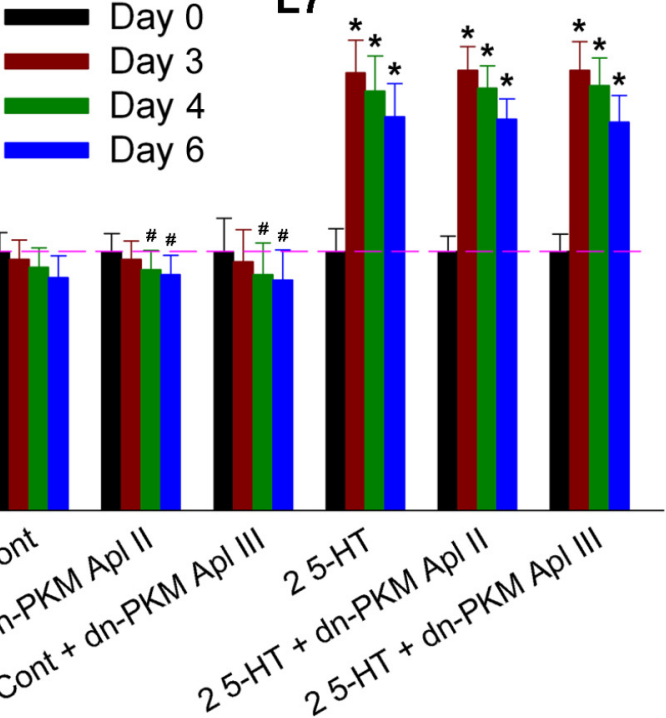

Figure 2. PKM ApI II or PKM ApI III activity in L7 is not required after day 3 to maintain nonassociative LTF. A, Experimental protocol. Persistent nonassociative LTF was evoked by repeated applications of $5-\mathrm{HT}$ on days 0 and 1 . Various constructs were injected into $\mathrm{L} 7$ on day 3 . B. Phase contrast views of sensorimotor cultures and epifluorescent views of construct expression in the same view area $24 \mathrm{~h}$ after injection. Scale bar, $50 \mu \mathrm{m}$. C, Examples of the change in the EPSP amplitudes in L7 over time for control and experimental groups. All experimental groups, receiving repeated applications of 5-HT (2 5-HT), showed an increase in EPSP amplitude that persisted to day 6, including those that were overexpressing dn-PKM Apl II or dn-PKM Apl III in L7. Overexpression of the dominant-negative constructs did not affect synaptic baseline in control. $\boldsymbol{D}$, Summary of the change in EPSP amplitudes for control and experimental groups. A two-factor ANOVA indicated a significant effect of treatment over time $\left(F_{(15,153)}=42.479 ; p<0.001\right)$. Individual comparisons indicated the following: (1) overexpression of dn-PKM Apl II or dn-PKM ApI III on day 3 in L7 after control treatment (Cont + dn-PKM Apl II; Cont + dn-PKM Apl III) had no significant effect on synaptic baseline compared with control (\#) on days 4 and 6 (Figure legend continues.) 
to block distinct forms of intermediate forms of facilitation (Bougie et al., 2012; Farah et al., 2016). Dominant-negative forms of enhanced green fluorescent protein (eGFP)-PKC Apl I and II were made previously (Manseau et al., 2001). Dominant-negative eGFP-PKC Apl I and eGFPPKC Apl II have a catalytic lysine converted to arginine, and the priming phosphorylation sites mutated were to glutamic acid for stabilization. These dominant-negatives have been shown to be effective at having isoform-specific effects at inhibiting physiological changes that are produced by activating their respective PKC isoforms (Manseau et al., 2001; Zhao et al., 2006; Lorenzetti et al., 2008; Hu et al., 2010). While PKCs do not dimerize, dominant-negative PKMs and PKCs compete for scaffolds and substrates with the endogenous PKCs, thus blocking their functional activity. The classical and SOL calpains were the most prominent calpains expressed in sensory and motor neurons, although other calpains also exist in Aplysia databases (Farah et al., 2016). The calpains were cloned by PCR based on transcriptosome data (Farah et al., 2016), and dominant-negative calpains were generated by converting the catalytic cysteine to serine (Farah et al., 2016). Many calpains act as dimers, and dominant-negative calpains could act by forming mutant heterodimers. Alternatively, dominant-negative calpains, similar to dominant-negative PKCs, may act by competing with endogenous calpains for substrates and scaffolds. The dominant-negative classical calpain (dn-classical) has been shown to be effective at blocking both the cleavage of PKCs using a FRET-based live imaging assay and the induction of intermediate facilitation, while dominant-negative SOL calpain (dn-SOL) did not have a significant effect in these experiments (Farah et al., 2016).

Microinjection was executed by a pneumatic picopump (PV820, World Precision Instruments). A solution of constructs $(0.3 \mu \mathrm{g} / \mu \mathrm{l}$ DNA in distilled water) containing $0.2 \%$ Fast Green was microinjected into the nuclei of sensory neurons or L7s on day 1 or 3 (see the protocol for each experiment). The tip of the micropipette was inserted into the cell nucleus. A short pressure pulse (20-50 ms duration; $20-40 \mathrm{psi}$ ) was delivered until the nucleus of the sensory neurons became uniformly green (Hu et al., 2010). Because the volume of the nucleus in L7 is $\sim 30 \times$ that of the nucleus of the sensory neuron, the pressure pulse (20-40 psi) of $600-1200 \mathrm{~ms}$ was delivered until the nucleus of L7 became uniformly green. The fluorescent images of construct expression were captured with a Nikon Diaphot microscope $24 \mathrm{~h}$ after injections.

Quantification and data analysis. All data are expressed as the mean \pm SEM produced by the indicated treatments. The EPSP amplitude was measured in millivolts $(\mathrm{mV})$. The initial EPSP amplitudes on day 0 were normalized as $100 \%$. The changes in EPSP amplitudes were measured by dividing the EPSP amplitudes on day 2, 3, 4, 5, or 6 by the EPSP amplitude on day 0 multiplied by $100 \%$. Some cultures expressing persistent LTF $(8 \%)$ had an increase in synaptic strength that was expressed as an action potential evoked in L7 on day 2 or 3 with the test stimulus to the sensory neurons. These cultures were excluded from all analyses. Overall, $91 \%$ of the remaining cultures survived to the final test point (day 5 or 6 ). All images were viewed with a Nikon Diaphot microscope attached to a silicon-intensified target video camera (Dage Series 68, Dage-MTI). Fluorescent intensity (arbitrary units) was measured by the Microcomputer-Controlled Imaging Device

$\leftarrow$

(Figure legend continued.) $\quad\left(F_{(5,51)}=0.0001\right.$ and 0.002 , all $p>0.8$ for dn-PKM Apl II; $F_{(5,51)}=0.003$ and 0.0001 , all $p>0.7$ for dn-PKM Apl III); (2) 25 -HT produced a significant increase in synaptic strength compared with each control group $\left({ }^{*}\right)$ on days 3,4 , and $6\left(F_{(5,51)}=\right.$ $2.997,2.758$, and 2.525 , all $p<0.05$ compared with Cont; $F_{(5,51)}=3.423,3.222$, and 2.744 , all $p<0.05$ compared with Cont $+\operatorname{dn}-$ PKM Apl II; $F_{(5,51)}=3.58,3.4$, and 2.929, all $p<0.01$ compared with Cont + dn-PKM Apl III); (3) overexpression of dn-PKM Apl II on day 3, the changes in synaptic strength evoked by $25-\mathrm{HT}$ (25-HT + dn-PKM ApI II) remained significantly greater than those in each control group $\left({ }^{*}\right)$ on days 4 and $6\left(F_{(5,51)}=3.593\right.$ and 3.174 , all $p<$ 0.01 compared with Cont; $F_{(5,51)}=4.381$ and 3.6 , all $p<0.01$ compared with Cont + dn-PKM Apl II) but were not significantly different from $25-\mathrm{HT}$ alone $\left(F_{(5,51)}=0.001\right.$ and 0.0001 , all $p>$ 0.9); (4) overexpressing dn-PKM ApI III on d 3, the change in synaptic strength evoked by $25-\mathrm{HT}$ (25-HT $+\mathrm{dn}-\mathrm{PKM}$ Ap IIII) remained significantly greater than that for each control group $\left({ }^{*}\right)$ on days 4 and $6\left(F_{(5,51)}=3.86\right.$ and 3.16 , all $p<0.01$ compared with Cont; $F_{(5,51)}=5.004$ and 3.863 , all $p<0.01$ compared with Cont $+\mathrm{dn}$-PKM ApI III) but were not significantly different from $25-\mathrm{HT}$ alone $\left(F_{(5,51)}=0.003\right.$ and $0.002 ;$ all $\left.p>0.8\right)$. software package (Imaging Research). ANOVA was used to assess overall significant differences, and Scheffé's $F$ test was used to gauge significant differences between individual treatments. Significant differences between specific groups in the histograms summarizing the changes in synaptic strength were indicated as follows: treatments that evoked a significant change $(p<0.05)$ compared with controls are designated with an asterisk $\left.{ }^{*}\right)$, treatments that resulted in changes in synaptic strength and were not significantly different from controls at any time point are designated with a hashtag (\#), treatments that resulted in significant changes in synaptic strength after stimuli such that at specific time points they were significantly different from other stimulated groups are designated with a small circle $(O)$.

\section{Results}

The role of PKC/PKM activities in maintaining long-term synaptic plasticity in mammals is controversial (Volk et al., 2013; Jalil et al., 2015; Tsokas et al., 2016)_compensatory substitutions are recruited under conditions when some isoforms are knocked down or out, suggesting roles for multiple PKC isoforms in longterm plasticity. In Aplysia, constitutive PKC activity is required for sustaining long-term plasticity at the behaviorally relevant sensorimotor synapse (Cai et al., 2011; Hu et al., 2011; Hu and Schacher, 2015). It is unclear, however, which isoforms of PKC or the constitutively active PKMs in the presynaptic and postsynaptic partner contributes to the persistence. We therefore used a dominant-negative approach to interfere with the activity of specific PKM or PKC isoforms on day 3 in either L7 or sensory neurons to determine whether the activities of specific isoforms starting $2 \mathrm{~d}$ after repeated applications of 5-HT or paired stimulation contributed to different forms of persistent plasticity. All of the dominant-negative constructs were kinase dead $(>95 \%)$ but were otherwise homologous to wild type to allow interactions with endogenous partners. As controls, we also examined whether the synaptic baseline was affected by reducing the activity of specific PKM or PKC isoforms in either L7 or sensory neurons starting on day 3 .

\section{Different cell-specific PKM isoforms maintain persistent nonassociative LTF}

Because constitutive PKC activity contributes to the maintenance of LTF (Cai et al., 2011; Hu and Schacher, 2015), we focused on the potential roles of the Aplysia PKM isoforms in L7 or sensory neurons by interfering with specific PKM isoform activity (Cameron et al., 2009; Bougie et al., 2012; Farah et al., 2016) starting 2 d after the last 5-HT application (Fig. 1A). The overexpression of the dominant-negative mRFP-tagged PKM isoforms and control construct (mRFP) were monitored by fluorescent microscopy $24 \mathrm{~h}$ after the construct was injected on day 3 (Figs. $1 B, 2 B$; see also $4 B, 5 B$ ). The mRFP control construct was expressed quite strongly and was detected throughout the sensory neuron or L7, while the mRFP-tagged dominant-negative constructs for each of the PKMs was expressed at equivalent levels in the cell body, axons, and neurites of L7 or sensory neurons independent of any changes in synaptic strength produced by a previous stimulation history on day 0 or 1 (Figs. $1 B, 2 B$; see also $4 B, 5 B$; data not shown). We examined the consequences of overexpressing each control or dominant-negative construct in L7 or sensory neurons on the persistence of nonassociative LTF produced by $2 \mathrm{~d}$ of brief applications of 5-HT (2 5-HT).

Overexpression of dn-mRFP-PKM Apl I in L7 resulted in the reversal of persistent nonassociative LTF (2 5-HT plus dn-PKM Apl I; $n=13$; Fig. $1 C, D)$. The decline in synaptic strength on days 4 and 6 was significant compared with the persistent nonassociative LTF expressed in cultures with no construct injection (2 5 -HT; $n=8$ ) or after injection of the control construct (2 5-HT 
A
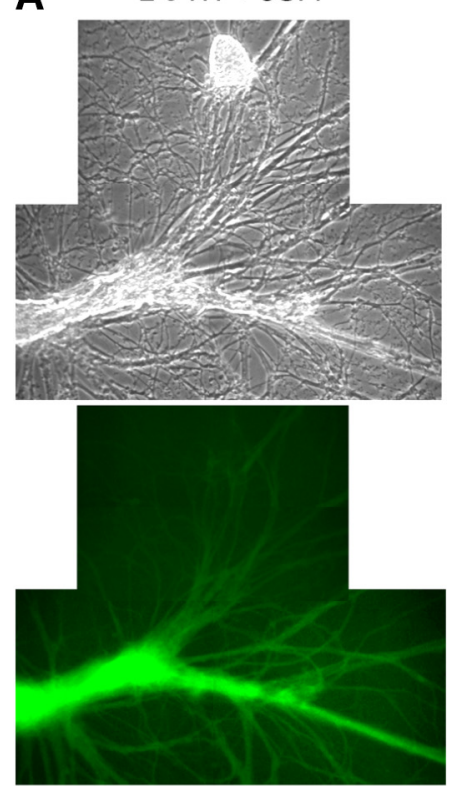

B

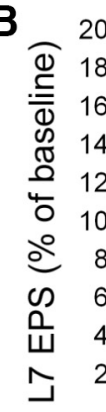

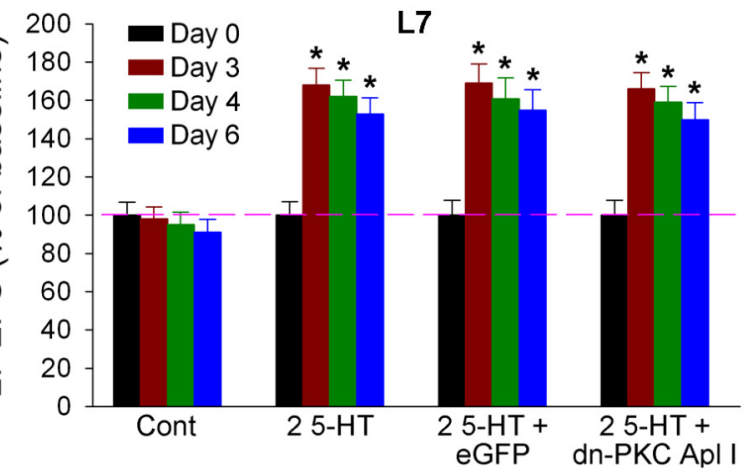

C

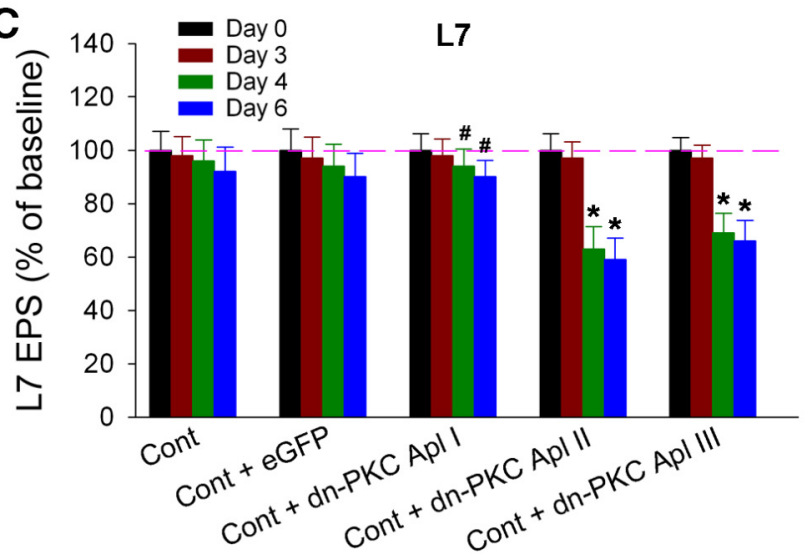

Figure 3. PKC Apl I activity in $\mathrm{L} 7$ is not required after day 3 to maintain nonassociative LTF. $A$, Phase contrast views of sensorimotor cultures and epifluorescent views of construct expression in the same view area (control and dominant-negative forms) in $\mathrm{L7} 24 \mathrm{~h}$ after injection. Scale bar, $50 \mu \mathrm{m}$. B, Summary of the change in the EPSP amplitude for control and experimental groups indicated that overexpression of dn-PKC Ap I in L7 (25-HT + dn-PKC Ap I ) failed to affect persistent nonassociative LTF. A two-factor ANOVA indicated a significant effect of treatment over time $\left(F_{(9,87)}=55.135 ; p<0.001\right)$. Individual comparisons indicated the following: (1) stimulation with 5 -HT produced a significant change in synaptic strength compared with control $(*)$ on days 3,4 , and $6\left(F_{(3,29)}=9.603,8.779\right.$, and 7.166 ; all $\left.p<0.01\right)$; (2) overexpressing control construct eGFP on day 3 had no significant effect on the change in synaptic strength evoked by $2 \mathrm{~d}$ of 5 -HT treatments ( $25-\mathrm{HT}+\mathrm{eGFP}$ ), which remained significantly greater than the change observed in control $\left({ }^{*}\right)$ on days 4 and $6\left(F_{(3,29)}=8.84\right.$ and 7.12 ; all $\left.p<0.01\right)$; and (3) After $2 \mathrm{~d}$ of 5 -HT treatments, overexpression of dn-PKCApI I (25-HT + dn-PKC Apl I) did not plus mRFP; $n=8$ ). The persistent facilitation was maintained on days 4 and 6 in these latter two groups compared with Cont $(n=$ 6) or with overexpression of the control construct (Cont plus mRFP; $n=8$ ). The decline in synaptic strength produced by the overexpression of dn-PKM Apl I was such that it was no longer significantly different from the control groups. Overexpression of dn-PKM Apl I in L7 after control treatment (Cont plus dnPKM Apl I; $n=6$ ) did not alter the synaptic baseline compared with control alone (Cont; $n=6$; Fig. 1C,D). Thus, PKM Apl I activity in L7 contributes to the maintenance of persistent nonassociative LTF.

Persistent nonassociative LTF was not reversed when overexpressing either dn-PKM Apl II (2 5-HT plus dn-PKM Apl II; $n=$ 13) or dn-PKM Apl III (2 5-HT plus dn-PKM Apl III; $n=15)$ in L7 starting $2 \mathrm{~d}$ after 5-HT treatments (Fig. 2). The increases in synaptic strength in both sets of cultures were comparable to the increase evoked by 25 -HT $(n=7)$. In the absence of any 5 -HT applications, the synaptic baseline was unaffected by the overexpression of dn-PKM Apl II (Cont plus dn-PKM Apl II; $n=8$ ) or by dn-PKM Apl III (Cont plus dn-PKM Apl III; $n=8$ ) compared with Cont $(n=6$; Fig. $2 C, D)$. Thus, reducing either PKM Apl II or PKM Apl III activity in L7 does not affect the maintenance of persistent nonassociative LTF.

We also examined whether the activity of classical PKC (PKC Apl I), novel PKC (PKC Apl II), or atypical PKC (PKC Apl III) in L7 or the sensory neurons might contribute to the maintenance of persistent nonassociative LTF. While dominant-negative PKCs and PKMs might be expected to have similar effects, the dominant-negative PKCs contain regulatory domain elements absent in the PKMs that may allow them to interact with additional scaffolds or substrates distinct from the PKMs. Alternatively, while all domains in PKM are present in PKC, inhibitory interactions between the regulatory domain and the catalytic domain may mask these interactions in dominant-negative PKCs, but not PKMs, and allow dominant-negative PKMs to have activities not shared with dominant-negative PKCs. The overexpression of the dominant-negative eGFP-tagged PKC isoforms and control construct (eGFP) were monitored by fluorescent microscopy $24 \mathrm{~h}$ after constructs were injected on day 3 (Fig. $3 A$; also see $6 A$ ). The eGFP construct was expressed quite strongly and was detected throughout L7 or sensory neurons, while each of the eGFP-tagged dominant-negative PKC constructs was expressed at equivalent levels in the cell body, axons, and neurites of L7 or sensory neurons independent of the previous stimulation history (data not shown). Each dominant-negative PKC con-

$\leftarrow$

significantly affect the change in synaptic strength compared with other 5 -HT-treated groups on days 4and $6\left(F_{(3,29)}=0.021\right.$ and 0.022 , all $p>0.8$ compared with $25-\mathrm{HT}$ alone; $F_{(3,29)}=0.007$ and 0.051 , all $p>0.8$ compared with $25-H T+e G F P)$, which remained significantly greater than the change in control $\left(F_{(3,29)}=8.84\right.$ and 7.12 , all $\left.p<0.01\right)$. C, Summary of the change in the EPSP amplitudes for various control groups with and without overexpression of the control construct or the dominantnegative constructs. A two-factor ANOVA indicated a significant effect of treatment over time $\left(F_{(12,123)}=23.302 ; p<0.001\right)$. Individual comparisons indicated the following:(1) overexpression of $\mathrm{dn}$-PKC Ap I lin L7 on day 3 after control treatment (Cont $+\mathrm{dn}$-PKC Ap I I) had no significant effect on synaptic baseline compared with control or control $+\mathrm{eGFP}(\#)$ on day $4\left(F_{(4,41)}=0.008\right.$ or 0.003 ; al $p>0.8)$ and day $6\left(F_{(4,41)}=0.007\right.$ or $0.004 ;$ all $\left.p>0.8\right)$; (2) overexpression of dn-PKC Apl II in L7 on day 3 after control treatment (Cont $+\mathrm{dn}$-PKC Apl II) had a significant effect (depression) on synaptic baseline compared with control or control $+\operatorname{eGFP}\left({ }^{*}\right)$ on day $4\left(F_{(4,41)}=2.203\right.$ or 2.097 ; all $\left.p<0.05\right)$ and day $6\left(F_{(4,41)}=1.997\right.$ or 2.113 ; all $\left.p<0.05\right)$; (3) overexpression of dn-PKC Apl III in L7 after control treatment on day 3 (Cont $+\mathrm{dn}$-PKC Apl III) had a significant effect (depression) on synaptic baseline compared with control or control $+\mathrm{eGFP}\left({ }^{*}\right)$ on day $4\left(F_{(4,41)}=2.211\right.$ or 1.989 ; all $\left.p<0.05\right)$ and day $6\left(F_{(4,41)}=1.933\right.$ or 1.987 ; all $\left.p<0.05\right)$. 


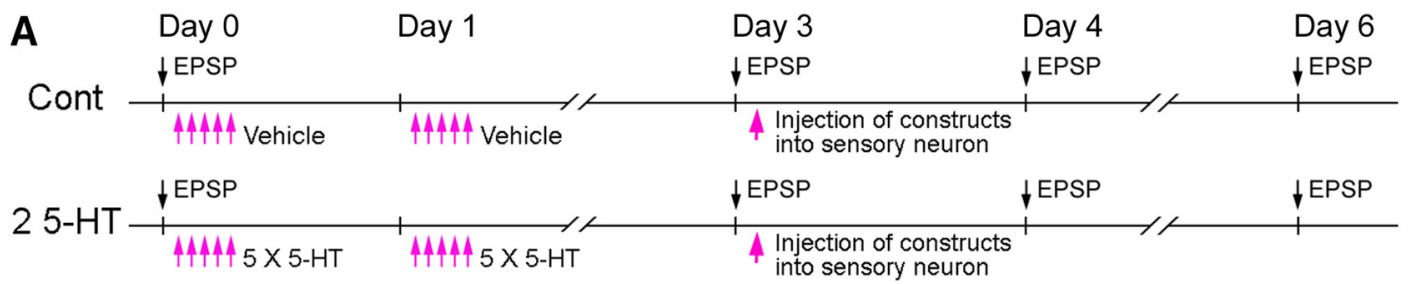

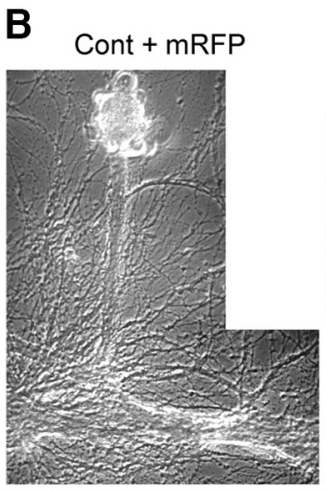

Cont + dn-PKM Apl I
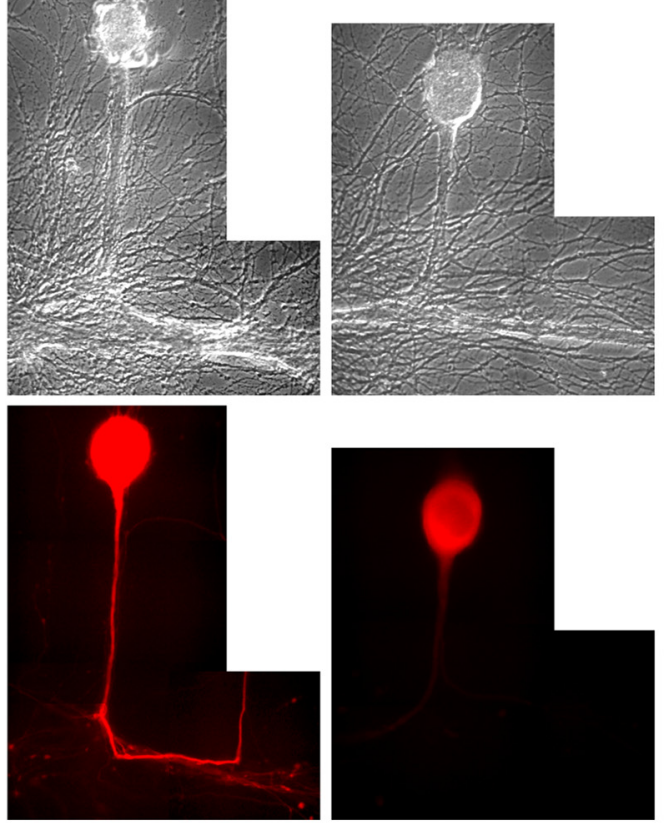

C

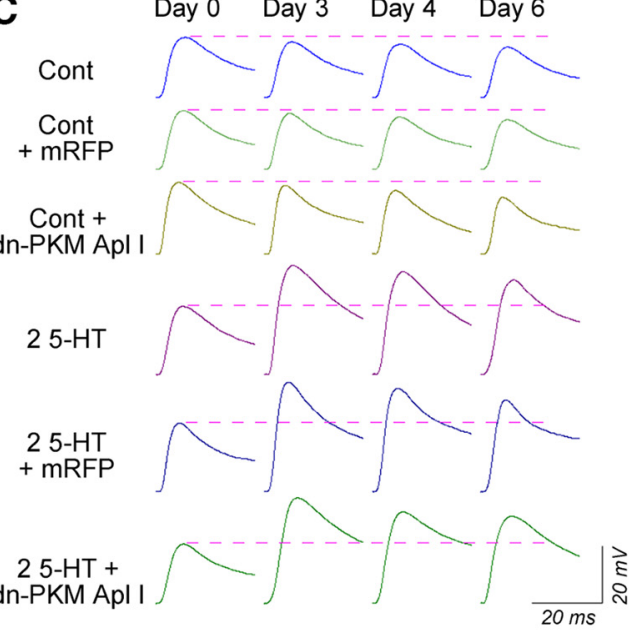

$25-\mathrm{HT}+\mathrm{mRFP}$
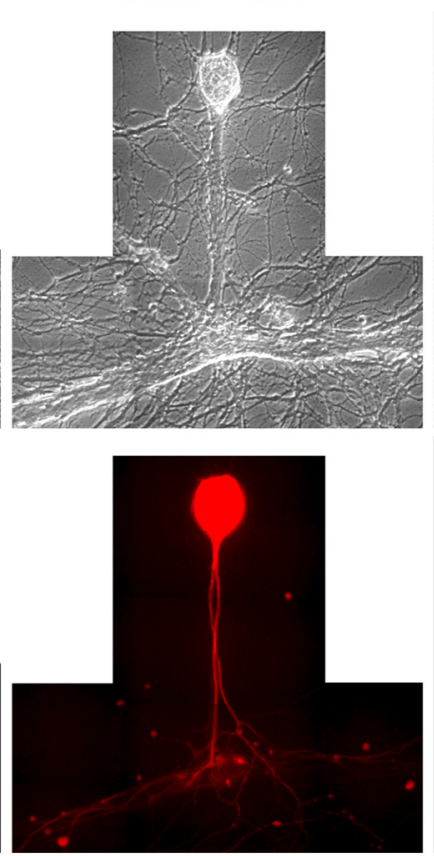

$25-\mathrm{HT}+$ dn-PKM Apl I
D

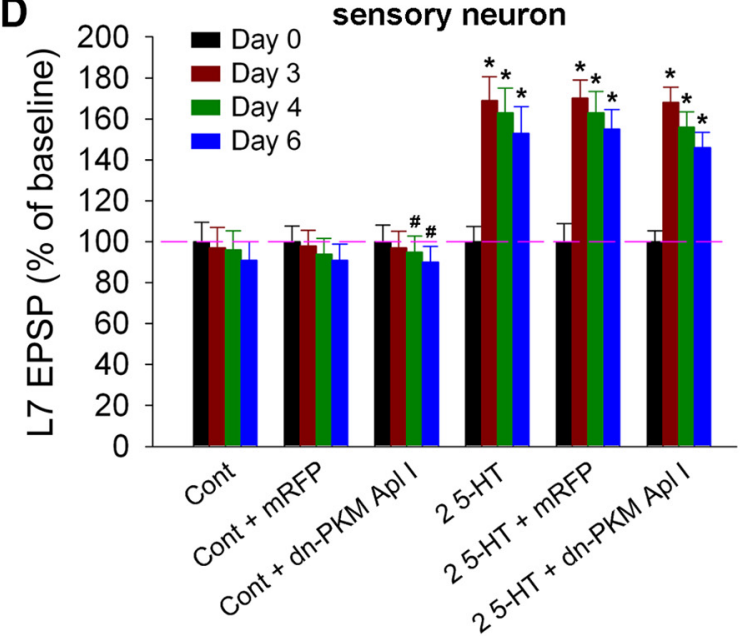

Figure 4. PKM Apl I activity in the sensory neurons is not required after day 3 to maintain nonassociative LTF. $A$, Experimental protocol for evoking persistent nonassociative LTF consisted of repeated applications of 5 -HT on days 0 and 1 of culture. EPSP amplitudes were tested before control or experimental treatments on day 0 and retested on days 3,4 , and 6 . Constructs were injected into sensory neurons on day 3. B. Phase contrast views of sensorimotor cultures and epifluorescent views of construct expression in the same view area (control and dominant-negative form constructs) in the sensory neurons $24 \mathrm{~h}$ after injection. Scale bar, $50 \mu \mathrm{m}$. C, Examples of the change in the EPSP amplitudes in L7 over time for control and experimental groups. Overexpression of dn-PKM Apl I after control treatment did not impact synaptic baseline. All experimental groups receiving repeated applications of 5-HT (25-HT) showed an increase in EPSP amplitude that persisted to day 6 , including those that were overexpressing dn-PKM ApI I in the sensory neurons. D, Summary of the change in the EPSP amplitude for control and experimental groups. A two-factor ANOVA indicated a significant effect of treatment over time $\left(F_{(15,141)}=66.941 ; p<0.001\right)$. Individual comparisons indicated the following: (1) overexpression of dn-PKM Apl I in the sensory neurons after control treatment (Cont + dn-PKM Apl I) had no significant effect on synaptic baseline compared with control or control + mRFP (\#) on day $4\left(F_{(5,47)}=0.004\right.$ or $0.002 ;$ all $\left.p>0.8\right)$ and day 6 $\left(F_{(5,47)}=0.005\right.$ or 0.011 ; all $\left.p>0.8\right) ;(2) 25$-HT produced a significant increase in synaptic strength $\left(^{*}\right)$ on days 3,4 , and 6 compared with those for each control group $\left(F_{(5,47)}=4.689,3.962\right.$. and 3.474 , all $p<0.01$ compared with Cont; $F_{(5,47)}=5.356,4.815$, and 3.961, all $p<0.01$ compared with Cont + mRFP; $F_{(5,47)}=5.431,4.675$, and 4.106, all $p<0.01$ compared with Cont + dn-PKM Apl I); (3) after 25-HT and overexpression of dn-PKM Ap I ( $25-\mathrm{HT}+\mathrm{dn}$-PKM Apl I) on day 3, the change in synaptic strength remained significantly greater than for each control group (*) on days 4 and $6\left(F_{(5,47)}=4.321\right.$ and $3.711, p<0.01$ compared with Cont; $F_{(5,47)}=5.586$ and $4.468, p<0.01$ compared with Cont + mRFP; $F_{(5,47)}=5.407$ and $4.653, p<0.01$ compared with Cont + dn-PKM Apl I), which was not significantly different from other 5 -HT-treated groups on days 4 and $6\left(F_{(5,47)}=0.061\right.$ and $0.064, p>0.7$ compared with $25-H \mathrm{~T}$ alone; $F_{(5,47)}=0.07$ and $0.107, p>$ 0.5 compared with 25-HT + mRFP). 


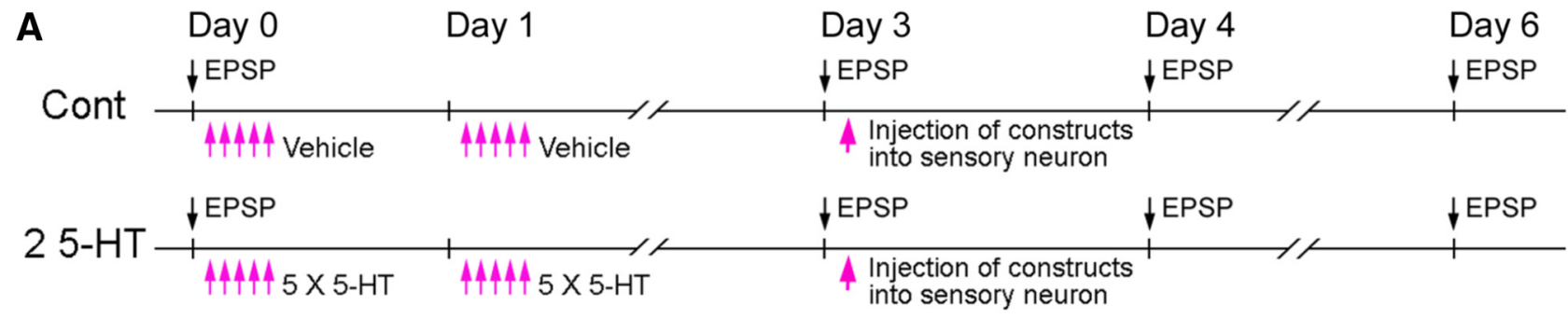

B

Cont + dn-PKM Apl II
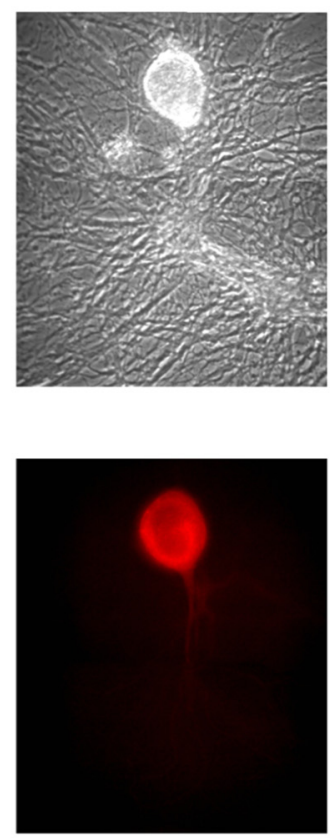

Cont + dn-PKM Apl III
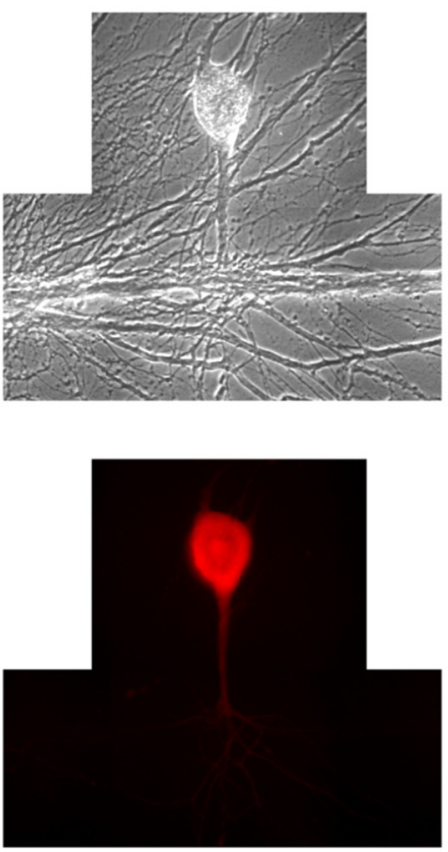

$25-\mathrm{HT}+$ dn-PKM Apl II
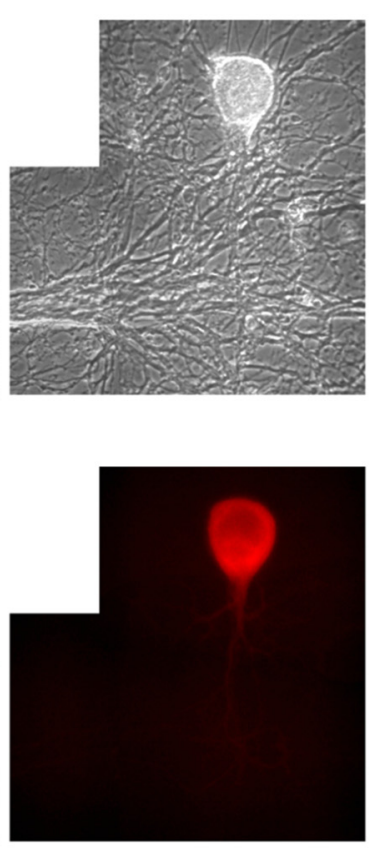

$25-\mathrm{HT}+$
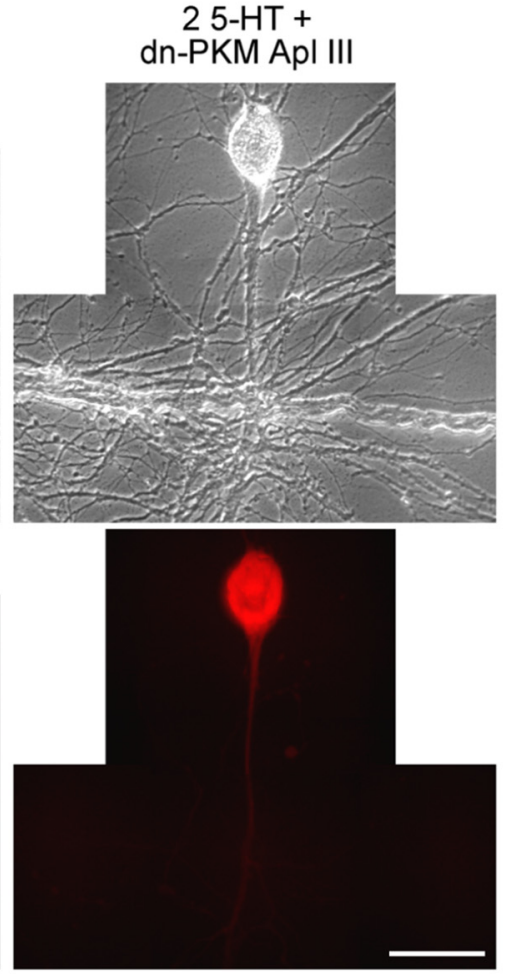

sensory neuron

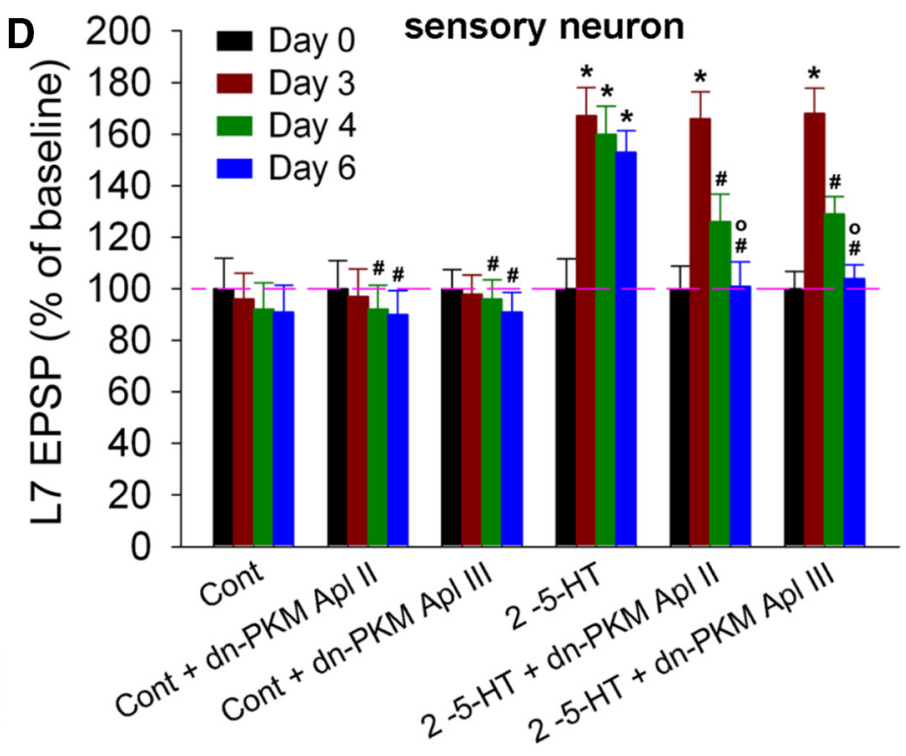

C Day 0 Day 3 Day 4 Day 6<smiles>C1C[C@H]2C[C@H]1C2</smiles><smiles>C1C2CC1C2</smiles>

Cont + dn-PKM ApI II<smiles>C1=CC2CCCCC12</smiles>

Cont + dn-PKM Apl III<smiles>C1CC2CC1C2</smiles><smiles>C1CCC2CCC2C1</smiles><smiles>C1CC2CCC2C1</smiles>

5-HT<smiles>CCC1(C)CC1</smiles><smiles>[CH-]1C2CCCC1CCC2</smiles>

2 5-HT + dn-PKM Apl II

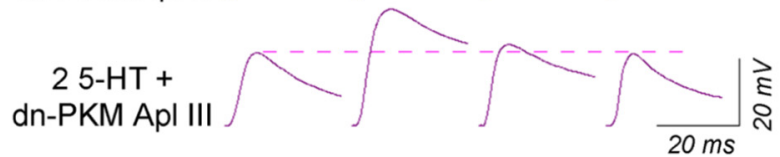

Figure 5. PKM Apl II or PKM Apl III activity in the sensory neurons is required after day 3 to maintain nonassociative LTF. $A$, Experimental protocol. Persistent nonassociative LTF was evoked by repeated applications of 5-HT on days 0 and 1. EPSP amplitudes were tested before control or experimental treatments on day 0 and were retested on days 3, 4, and 6. Constructs for dn-PKM ApI II or dn-PKM Apl III were injected into sensory neurons on day 3. B, Phase contrast views of sensorimotor cultures and epifluorescent views of construct expression in the same view area $24 \mathrm{~h}$ after injection. Scale bar, $50 \mu \mathrm{m}$. C, Examples of the change in the EPSP amplitudes in L7 over time for control and experimental groups. Overexpression of dn-PKM Apl II or dn-PKM ApI III in the sensory neurons reversed nonassociative LTF and had no effect on synaptic baseline in control. $\boldsymbol{D}$, Summary of the change in the EPSP amplitudes for control and experimental groups. A two-factor ANOVA indicates a significant effect of treatment over time $\left(F_{(15,144)}=33.39 ; p<0.001\right)$. Individual comparisons indicated the following: (1) overexpression of dn-PKM Apl II or dn-PKM Apl III in the sensory neurons after control treatment (Cont $+\mathrm{dn}$-PKM Apl II; Cont $+\mathrm{dn}$-PKM Apl III) had no significant effect on the synaptic baseline compared with control (\#) on (Figure legend continues.) 
struct was shown previously to have isoform-specific effects on inhibiting physiological changes that are produced by activating their respective PKC isoforms (Manseau et al., 2001; Zhao et al., 2006; Lorenzetti et al., 2008; Hu et al., 2010).

Overexpression of dn-PKC Apl I in L7 on day 3 (Fig. 3B) did not significantly affect the maintenance of persistent nonassociative LTF (2 5-HT plus dn-PKC Apl I; $n=10$ ) compared with the increases in synaptic strength evoked by 25 -HT $(n=7)$ or by 2 5 -HT plus overexpression of the control construct (2 5-HT plus eGFP; $n=7$ ). Overexpression of dn-PKC Apl I (Cont plus dnPKC Apl I; $n=10$ ) in L7 on day 3 failed to affect the synaptic baseline (Fig. $3 C$ ). In contrast, the overexpression of dn-PKC Apl II $(n=12)$ or dn-PKC Apl III $(n=10)$ in L7 on day 3 resulted in a significant decline in synaptic baseline (Fig. $3 C$ ) compared with overexpression of the control construct eGFP (Cont plus eGFP; $n=7)$. Since the overexpression of dn-PKC Apl II or dn-PKC Apl III in L7 affected the synaptic baseline, we could not test their role in maintaining persistent LTF; we cannot distinguish between a reversal of the synaptic plasticity and a decrease in the basal synaptic strength (the synaptic baseline). The results suggest that PKM Apl I, but not PKC Apl I, in L7 contributes to the persistence of nonassociative LTF. In addition, PKC Apl II and PKC Apl III differ from their respective PKM counterparts in that interfering with the activity of each of the PKC isoforms affects the synaptic baseline.

Different PKM isoforms in the sensory neurons are required for maintaining persistent nonassociative LTF (Figs. 4, 5). Overexpression of dn-PKM Apl I in the sensory neurons failed to reverse persistent nonassociative LTF (2 5-HT plus dn-PKM Apl I; $n=16$; Fig. 4). The increase in synaptic strength observed after injection of dn-PKM Apl I was comparable to the increase evoked by 25 -HT $(n=7)$ or the increase after injection of the control construct in the sensory neurons (25-HT plus mRFP; $n=8$ ). The increase in synaptic strength was also significantly greater than that in the Cont $(n=6)$ or after injection of the control construct (Cont plus mRFP; $n=8$ ). In addition, overexpression of dnPKM Apl I in the sensory neurons (Cont plus dn-PKM Apl I; $n=8$ ) did not affect the synaptic baseline (Fig. 4C,D). Unlike the results with L7, reducing PKM Apl I activity in the sensory neurons days after 5-HT treatments does not affect the maintenance of nonassociative LTF.

Persistent nonassociative LTF was reversed after overexpressing dn-PKM Apl II (2 5-HT plus dn-PKM Apl II; $n=10$ ) or dn-PKM Apl III (2 5-HT plus dn-PKM Apl III; $n=15$ ) in the sensory neurons (Fig. 5). The increases in synaptic strength in both sets of cultures on day 3 before construct injection were

\section{$\leftarrow$}

(Figure legend continued.) days 4 and $6\left(F_{(5,48)}=0.002\right.$ and 0.001 , all $p>0.8$ for dn-PKM Apl $\| F_{(5,48)}=0.018$ and 0.0002 , all $p>0.7$ for dn-PKM ApI III); (2) 25-HT produced a significant increase in the change in synaptic strength compared with each control group $(*)$ on days 3,4 , and $6\left(F_{(5,48)}=3.513,4.190\right.$, and 4.624, all $p<0.01$ compared with Cont; $F_{(5,48)}=3.685$, 4.499 , and 5.170 , all $p<0.01$ compared with Cont + dn-PKM ApIII; $F_{(5,48)}=3.838,4.269$ and 5332, all $p<0.01$ compared with Cont + dn-PKM ApI III); (3) after 25-HT and overexpression of dn-PKM ApI II (25-HT + dn-PKM ApI II) on day 3, the change in synaptic strength was not significantly different from Cont or Cont + dn-PKM ApI II (\#) on day $4\left(F_{(5,48)}=1.186\right.$ or 1.267; all $p>0.1)$ and day $6\left(F_{(5,48)}=0.132\right.$ or 0.170 ; all $\left.p>0.5\right)$; (4) after 25 -HT treatments and overexpression of dn-PKM Apl III (2 5-HT + dn-PKM Apl III) on day 3, the change in synaptic strength was not significantly different from Cont or Cont + dn-PKM ApI III (\#) on day 4 $\left(F_{(5,48)}=1.541\right.$ or 1.451 ; all $\left.p>0.1\right)$ and day $6\left(F_{(5,48)}=0.250\right.$ or 0.286 ; all $\left.p>0.5\right)$; $(5)$ after 25 -HT treatments and overexpression of dn-PKM Apl II or dn-PKM Apl III, the changes in synaptic strength were significantly smaller $(\boldsymbol{O})$ than the change detected in 25 -HT alone on day $6\left(F_{(5,48)}=4.213\right.$ or 4.412 ; all $\left.p<0.01\right)$. significantly reduced on days 4 and 6 after overexpression of dn-PKM Apl II or dn-PKM Apl III. These reversals of the increases in synaptic strength were significant compared with the increase evoked by 25 -HT $(n=8)$. Overexpression of either dn-PKM Apl II (Cont plus dn-PKM Apl II; $n=7$ ) or dn-PKM Apl III (Cont plus dn-PKM Apl III; $n=8$ ) in the sensory neurons after control treatments did not affect the synaptic baseline, and synaptic strengths were comparable to those of Cont alone $(n=$ 6; Fig. $5 C, D$ ). Thus, unlike the results observed with $\mathrm{L7}$, in the sensory neurons PKM Apl II and PKM Apl III activity contributes to maintaining persistent nonassociative LTF, while PKM Apl I activity does not.

We also examined whether the activity of PKC Apl I, PKC Apl II, or PKC Apl III in the sensory neurons might contribute to the persistence of nonassociative LTF. Control and dominantnegative constructs were overexpressed in the sensory neurons (Fig. 6A). Overexpression of dn-PKC Apl I in the sensory neurons on day 3 (Fig. $6 B$ ) did not significantly affect the maintenance of persistent nonassociative LTF (2 5-HT plus dn-PKC Apl I; $n=8$ ) compared with the increases in synaptic strength evoked by 2 5 -HT $(n=7)$ or by 25 -HT plus overexpression of the control construct (2 5-HT plus eGFP; $n=7$ ). Overexpression of dn-PKC Apl I (Cont plus dn-PKC Apl I; $n=8$ ) in the sensory neurons on day 3 failed to affect the synaptic baseline (Fig. $6 C$ ). In contrast, overexpression of dn-PKC Apl II $(n=10)$ or dn-PKC Apl III $(n=10)$ in the sensory neurons on day 3 resulted in a significant decline in synaptic baseline (Fig. 6C) compared with overexpression of the control construct eGFP (Cont plus eGFP; $n=7$ ) or control alone. Similar to the L7 motor neuron, because the overexpression of dn-PKC Apl II or dn-PKC Apl III in the sensory neurons decreased the synaptic baseline, we could not test their role in maintaining persistent LTF. The results suggest that the activity of PKM Apl II or PKM Apl III, but not PKM Apl I or PKC Apl I, in the sensory neurons even several days after 5-HT applications, is required to sustain persistent nonassociative LTF.

\section{Different set of cell-specific PKM isoforms maintain persistent associative LTF}

Do activities of the same PKM isoforms in L7 or sensory neurons maintain persistent associative LTF produced by two pairings of activity plus 5-HT (Fig. 7A)? In L7 (Fig. 7B), overexpression of dn-PKM Apl II [2 (Tet plus 5-HT) plus dn-PKM Apl II; $n=11$ ] or dn-PKM Apl III [2 (Tet plus 5-HT) plus dn-PKM Apl III; $n=$ 12] on day 3 resulted in the reversal of persistent associative LTF on days 4 and 6 . The change in synaptic strength was significantly reduced compared with the persistent associative LTF evoked after paired stimulation alone [2 (Tet plus 5-HT); $n=8$ ] or when L7 was expressed a control construct [2 (Tet plus 5-HT) plus mRFP; $n=8$ ]. In contrast, overexpression of dn-PKM Apl I in L7 [2 (Tet plus 5-HT) plus dn-PKM Apl I; $n=10$ ] failed to reverse persistent associative LTF on days 4 and 6 (Fig. $7 B$ ). The level of facilitation was not significantly different from the facilitation produced by paired stimulation alone or paired stimulation plus overexpression of the control construct in L7. Thus, the PKM activities in L7 that maintain persistent associative LTFPKM Apl II and PKM Apl III, but not PKM Apl I-are the opposite of the PKMs in L7 that maintain nonassociative LTF-PKM Apl I, but not PKM Apl II or PKM Apl III.

In the sensory neurons, overexpression of dn-PKM Apl I or dn-PKM Apl III failed to reverse persistent associative LTF produced by two pairings of activity plus 5-HT (Fig. 7C). Overexpression of dn-PKM Apl I [2 (Tet plus 5-HT) plus dn-PKM Apl I; $n=8]$ on day 3 failed to affect the facilitation evoked by two 
A
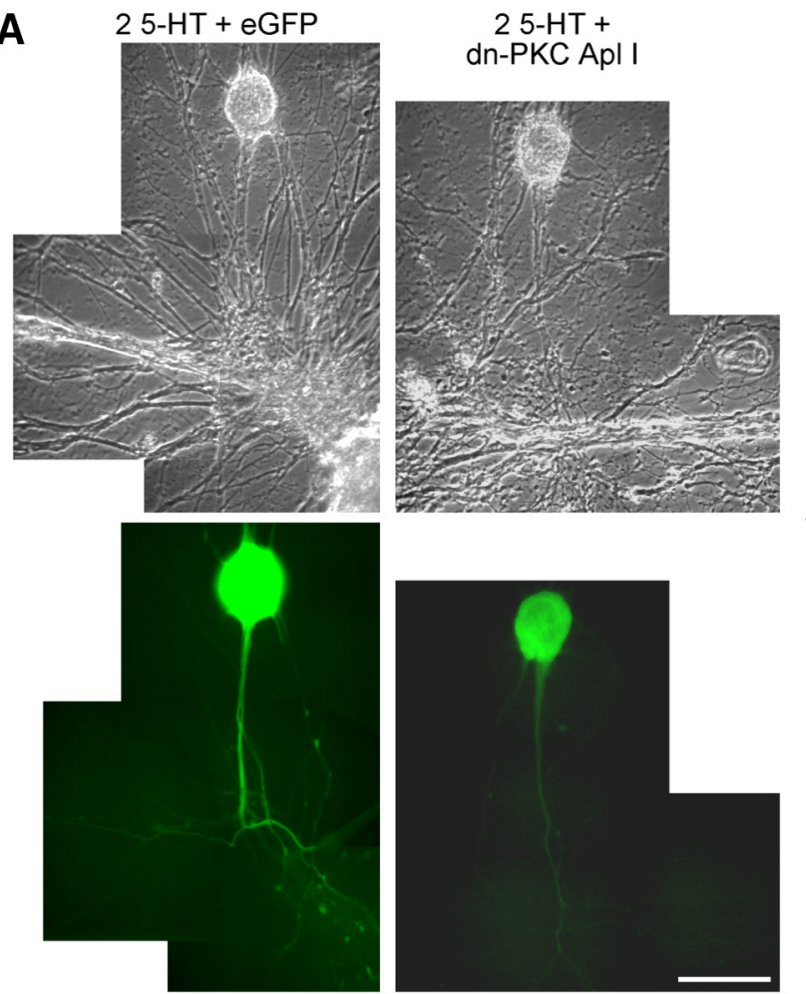

B
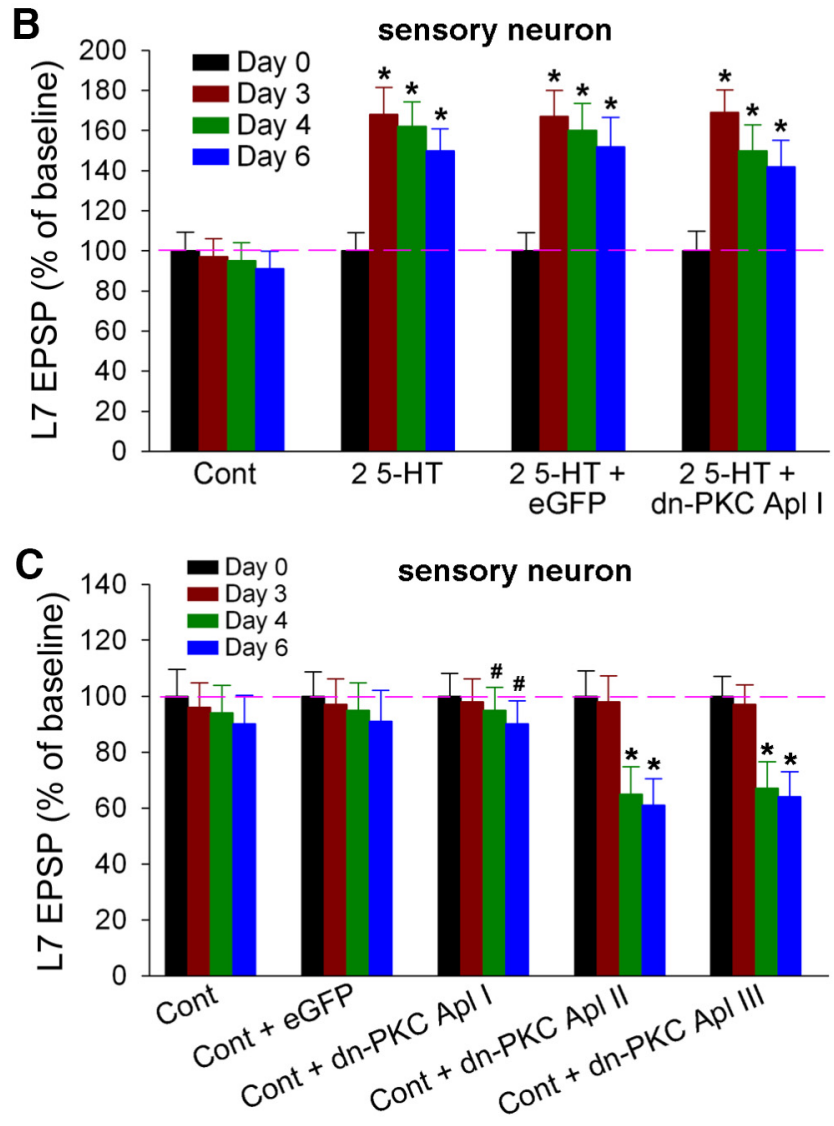

Figure 6. PKC Apl I activity in the sensory neurons is not required after day 3 to maintain nonassociative LTF. $\boldsymbol{A}$, Phase contrast views of sensorimotor cultures and epifluorescent views of construct expression in the same view area (control and dominant-negative forms) in the sensory neurons $24 \mathrm{~h}$ after injection. Scale bar, $50 \mu \mathrm{m}$. $\boldsymbol{B}$, Summary of the change in the EPSP amplitude for control and experimental groups indicated that overexpression of $\mathrm{dn}$-PKC ApI I in the sensory neurons (2 5-HT $+\mathrm{dn}$-PKC Apl I) failed to affect persistent nonassociative LTF. A two-factor ANOVA indicated a significant effect of treatment over time $\left(F_{(9,72)}=32.47\right.$; pairings of stimuli on days 4 and 6 compared with the change observed in 2 (Tet plus 5-HT) $(n=6)$ or following the expression of a control construct [2 (Tet plus 5-HT) plus mRFP; $n=7$ ]. Overexpression of dn-PKM Apl III $(n=8)$ also failed to reverse the increase in synaptic strength produced by two pairings. In contrast, overexpression of dn-PKM Apl II $(n=10)$ in the sensory neurons reversed associative LTF on days 4 and 6 . The change in synaptic strength was no longer significantly different from that of the control $(n=6)$. Thus, PKM Apl II activity in the sensory neurons maintains associative LTF, while both PKM Apl II and PKM Apl III activities in the sensory neurons maintain nonassociative LTF.

We also examined whether PKC Apl I was required for the expression of persistent associative LTF. Overexpression of dominant-negative PKC Apl I in either L7 or sensory neurons failed to interfere with associative LTF (data not shown). Dominant-negative PKC Apl I in the sensory neurons did affect a property that is characteristic of persistent associative LTF-the altered kinetics of homosynaptic depression (HSD) produced by low-frequency stimulation of the sensory neuron (Hu and Schacher, 2015). Overexpression of dominant-negative PKC Apl I, but not dominant-negative PKM Apl I or PKM Apl III, reversed HSD kinetics back to control levels (data not shown). Overexpression of dominant-negative PKM Apl II in the sensory neurons, which reversed persistent associative LTF (Fig. 7) also reversed the kinetics of HSD back to control levels (data not shown). As shown previously (Hu and Schacher, 2015), all manipulations that reversed persistent associative LTF (even overexpression of specific dominant-negative PKMs in L7) reversed the attenuated kinetics of HSD back to control levels (data not shown). Thus, PKC Apl I activity in the sensory neurons has a more restricted role in persistent associative LTF.

Activity of classical or SOL calpain is not required for the maintenance of persistent LTF but is required for the expression of persistent LTF

The Aplysia PKMs are generated by the action of calpains on their respective PKC isoforms (Bougie et al., 2009, 2012; Farah et al., 2016). Are calpain activities critical for the constitutive presence of PKM activities days after 5-HT applications or paired stimuli that generated the different forms of persistent plas-

\footnotetext{
$\leftarrow$

$p<0.001$ ). Individual comparisons indicated the following: (1) stimulation with $2 \mathrm{~d}$ of $5-\mathrm{HT}$ applications (25-HT or 25-HT + eGFP) produced a significant increase in the change in synaptic strength compared with control $\left(^{*}\right)$ on day $3\left(F_{(3,24)}=5.231\right.$ or 4.982 ; all $\left.p<0.01\right)$, day 4 $\left(F_{(3,24)}=4.503\right.$ or 4.333 ; all $\left.p<0.01\right)$, and day $6\left(F_{(3,24)}=3.535\right.$ or 3.759 ; all $\left.p<0.01\right) ;(2)$ after 5-HT treatments, overexpression of dn-PKC Apl I on day 3 in the sensory neurons had no significant effect on the change in synaptic strength, which remained significantly greater than the change observed in control $(*)$ on days 4 and $6\left(F_{(3,24)}=3.777\right.$ and 3.35 ; all $\left.p<0.01\right)$. C, Summary of the change in the EPSP amplitudes for various control groups with/without overexpression of dominant-negative PKCs constructs. A two-factor ANOVA indicated a significant effect of treatment over time $\left(F_{(12,105)}=28.059 ; p<0.001\right)$. Individual comparisons indicated the following: (1) overexpression of dn-PKC Apl I in the sensory neurons on day 3 after control treatment (Cont $+\mathrm{dn}$-PKC Apl I) had no significant effect on synaptic baseline compared with control or control + eGFP (\#) on day $4\left(F_{(4,35)}=0.002\right.$ or $0.0001 ;$ all $\left.p>0.8\right)$ and day $6\left(F_{(4,35)}=0.0004\right.$ or 0.0002 ; all $\left.p>0.9\right)$; (2) overexpression of dn-PKC Apl II in the sensory neurons on day 3 after control treatment (Cont + dn-PKC Apl II) had a significant effect (depression) on synaptic baseline compared with control or control + eGFP $\left({ }^{*}\right)$ on day 4 $\left(F_{(4,35)}=2.053\right.$ or 2.217 ; all $\left.p<0.05\right)$ and day $6\left(F_{(4,35)}=1.962\right.$ or 2.111 ; all $\left.p<0.05\right) ;(3)$ overexpression of dn-PKC Apl III in the sensory neurons on day 3 after control treatment (Cont $+\mathrm{dn}$-PKC Apl III) had a significant effect (depression) on synaptic baseline compared with control or control + eGFP $\left(^{*}\right)$ on day $4\left(F_{(4,35)}=1.906\right.$ or 1.974 ; all $\left.p<0.05\right)$ and day 6 $\left(F_{(4,35)}=1.967\right.$ or 1.911 ; all $\left.p<0.05\right)$.
} 

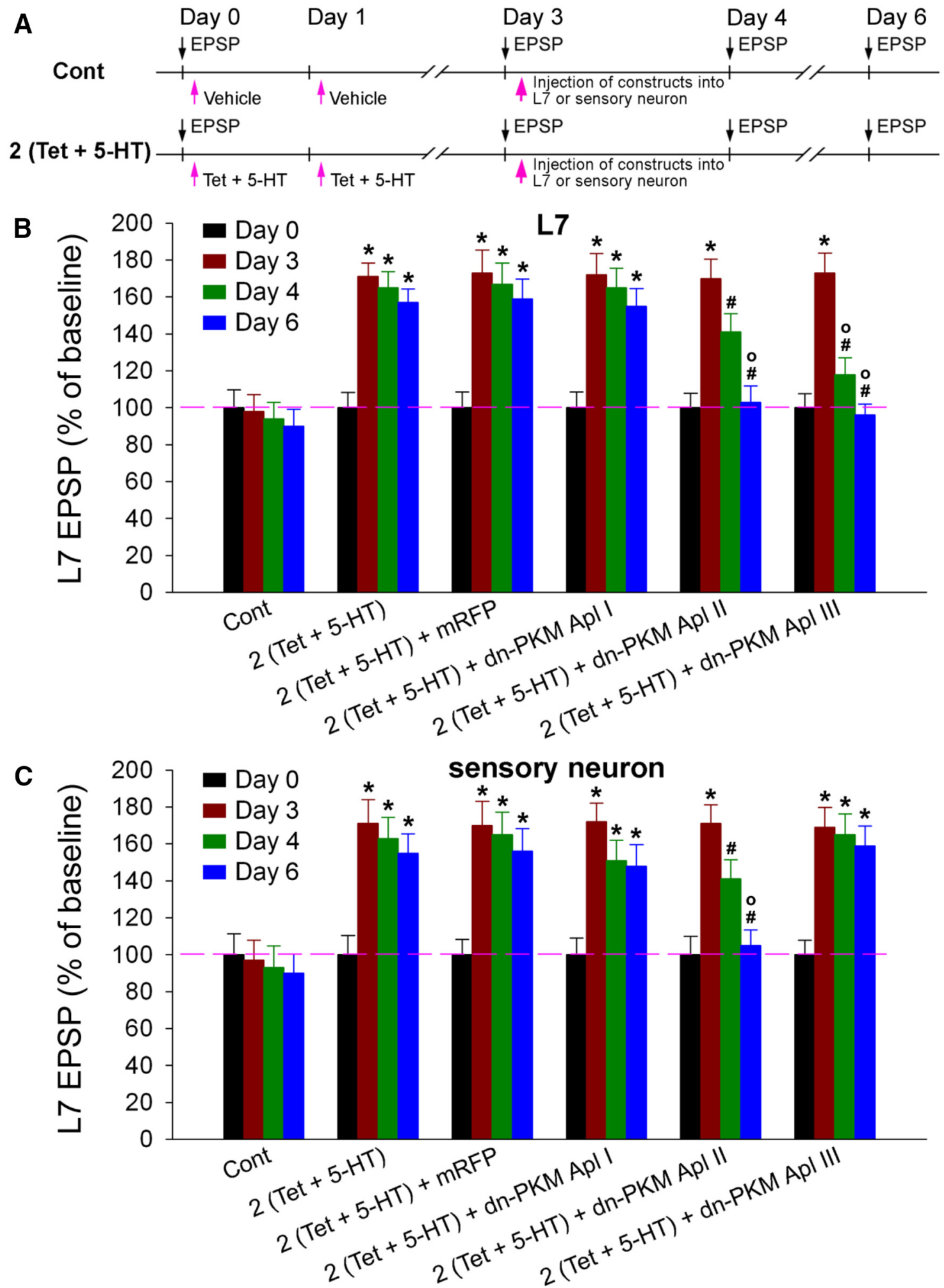

Figure 7. PKM ApI II or PKM ApI III activity in L7 or PKM Apl II activity in the sensory neurons is required to maintain persistent associative LTF. A, Experimental protocol for evoking persistent associative LTF consisted of pairing action potential activity in the sensory neurons $(20 \mathrm{~Hz}$ for $2 \mathrm{~s})$ with a brief application of 5 -HT on days 0 and 1 . EPSP amplitudes were tested before control or experimental treatments on day 0 and were retested on days 3,4 , and 6 . Control or experimental constructs were injected into $L 7$ or sensory neuron on day 3 . B, Summary of the change in the EPSP amplitudes for control and experimental groups after overexpression of constructs in L7. A two-factor ANOVA indicated a significant effect of treatment over time $\left(F_{(15,150)}=30.154 ; p<0.001\right)$. Individual comparisons indicated the following: (1) all groups with two pairings of stimuli produced a significant increase in the change in synaptic strength compared with control $(*)$ on day 3 $\left[F_{(5,50)}=3.687\right.$ for 2 (Tet + 5-HT), 3.814 for 2 (Tet + 5-HT) + mRFP, 4.15 for 2 (Tet + 5-HT) + dn-PKM Apl I, 4.134 for 2 (Tet + 5-HT) + dn-PKM Apl II, and 4.567 for 2 (Tet + 5-HT) + dn-PKM Apl III; all $p<0.01]$; (2) after two pairings of stimuli and overexpression of dn-PKM Apl I [2 (Tet + 5-HT) + dn-PKM Ap I] in L7, the change in synaptic strength remained significantly greater than that for control $(*)$ on day $4\left(F_{(5,50)}=4.535 ; p<0.01\right)$ and day $6\left(F_{(5,50)}=5.096 ; p<0.01\right) ;(3)$ after two pairings of stimuli and overexpression of dn-PKM ApI II [2 (Tet +5 -HT) + dn-PKM ApI II] in $\mathrm{L} 7$, the change in synaptic strength was not significantly different from that for control (\#) on days 4 and $6\left(F_{(5,50)}=1.077\right.$ and 0.208 ; all $\left.p>0.1\right)$, which were significantly smaller (o) than the change detected in 2 (Tet +5 - $\mathrm{HT}$ ) alone on day $6\left(F_{(5,50)}=3.844 ; p<0.01\right)$; $(4)$ after two pairings of stimuli and overexpression of dn-PKM Apl III (Figure legend continues.) 
ticity? Dominant-negative versions of two calpain isoforms, classical or SOL, were injected into L7 or sensory neurons on day 3, the same time as the injections of dn-PKMs and dnPKCs. Dominant-negative calpains may inhibit calpains by forming inactive dimers or by competing for binding with scaffolds or substrates. The dominant-negative classical calpain blocks both the cleavage of a FRET-sensitive reporter of Aplysia PKCs and the induction of plasticity during intermediate forms of facilitation (Farah et al., 2016). The persistent increases in synaptic strength evoked by repeated applications of 5-HT (nonassociative LTF) or by two pairings of activity and 5-HT (associative LTF) were unaffected by the overexpression of the dominant-negatives of either calpain isoform in L7 (Fig. $8 A, C$ ) or in the sensory neurons (Fig. $8 B, D$ ) after day 3. Overexpressing each dominant-negative calpain had no significant effect on synaptic baseline. Thus, it appears that the constitutive activations of the PKMs, days after 5-HT applications or paired stimuli that produce different forms of persistent LTF do not require the activities of classical or SOL calpain.

Are calpain activities required earlier for the expression of the different forms of persistent LTF? We injected the different dominant-negative calpains into L7 or sensory neurons on day 1 , $4-5 \mathrm{~h}$ after the second set of stimuli (Fig. $9 A, D)$ and examined the changes in synaptic strength on days 2,3 , and 5 . Because of the earlier time of injection of the dominant-negatives, changes in the expression of LTF could be due to a block in the induction of the persistent LTF, a reversal in the initial phases of LTF from stimulation on day 0 , day 1 , or both.

Overexpression of dn-SOL in L7 on day 1 blocked the expression of persistent nonassociative LTF (Fig. 9B). Compared with the increase in synaptic strength produced by $2 \mathrm{~d}$ of 5-HT applications $(n=6)$, the synaptic strength after injection of dn-SOL $(n=8)$ was significantly smaller on days 3 and 5 . In contrast, overexpression of dn-classical $(n=8)$ in L7 on day 1 did not significantly change the increase in synaptic strength of persistent nonassociative LTF on days 2, 3, and 5. Overexpression of dnSOL $(n=6)$ or dn-classical $(n=6)$ in L7 after control treatments did not affect the synaptic baseline compared with Cont alone $(n=6$; Fig. 9B).

Overexpression of dn-SOL in the sensory neurons on day 1 also blocked the expression of persistent nonassociative LTF (Fig.

\section{$\leftarrow$}

(Figure legend continued.) $\quad[2$ (Tet +5 -HT) + dn-PKM Apl III] in L7, the changes in synaptic strength were not significantly different from those of control $(\#)$ on days 4 and $6\left(F_{(5,50)}=\right.$ 0.551 and 0.045 ; all $p>0.1$, which were significantly smaller ( $\mathbf{o}$ ) than the changes detected in 2 (Tet $+5-\mathrm{HT}$ ) on days 4 and $6\left(F_{(5,50)}=2.302\right.$ and $5.10 ; p<0.05$ and 0.01$)$. C, Summary of the change in the EPSP amplitudes for control and experimental groups after overexpression of constructs in the sensory neurons. A two-factor ANOVA indicated a significant effect of treatment over time $\left(F_{(15,117)}=30.764 ; p<0.001\right)$. Individual comparisons indicated the following: (1) all groups with two pairings of stimuli produced a significant increase in the change in synaptic strength compared with control $(*)$ on day $3\left[F_{(5,50)}=3.446\right.$ for 2 (Tet +5 -HT), 3.67 for 2 (Tet + 5-HT) + mRFP, 4.009 for 2 (Tet + 5-HT) + dn-PKM Apl I, 4.28 for 2 (Tet + 5-HT) + dn-PKM Apl II, 3.772 for 2 (Tet +5 -HT) + dn-PKM Apl III; all $p<0.01]$; (2) after two pairings of stimuli and overexpression of either dn-PKM Apl I [2 (Tet $+5-\mathrm{HT})+$ dn-PKM ApI I] or dn-PKM Apl III [2 (Tet $+5-H T)+$ dn-PKM ApI III] in the sensory neurons, the changes in synaptic strength remained significantly greater than those for control $\left(^{*}\right)$ on day $4\left(F_{(5,39)}=\right.$ 2.387 or $3.660 ; p<0.05$ or 0.01$)$ and day $6\left(F_{(5,39)}=2.681\right.$ or $3.779 ; p<0.05$ or 0.01$)$; (3) after two pairings of stimuli and overexpression of dn-PKM ApI II [2 (Tet + 5-HT) + dn-PKM ApI II] in the sensory neurons, the changes in synaptic strength were not significantly different from those for control (\#) on day $4\left(F_{(5,39)}=1.810 ; p>0.05\right)$ and day $6\left(F_{(5,39)}=0.209 ; p>0.3\right)$, which were significantly smaller $(\boldsymbol{o})$ than the changes detected in 2 (Tet $+5-\mathrm{HT}$ ) on day 6 $\left(F_{(5,39)}=2.192 ; p<0.05\right)$.
9C). Compared with the increases in synaptic strengths produced by 25 -HT $(n=6)$, the change in synaptic strengths after the injection of dn-SOL $(n=8)$ was significantly smaller on days 2,3 , and 5. In contrast, overexpression of dn-classical in the sensory neurons on day $1(n=8)$ did not significantly affect persistent nonassociative LTF. Overexpression of dn-SOL $(n=6)$ or $\mathrm{dn}$ classical $(n=6)$ in the sensory neurons after control treatments did not affect the synaptic baseline compared with Cont alone $(n=6$; Fig. 9 C). Thus, the activity of SOL calpain, but not classical calpain, both in the sensory neurons and in L7, is required for the expression of persistent nonassociative LTF.

Persistent associative LTF produced by two pairings of tetanus plus 5-HT required the activity of classical calpain, but not SOL calpain, in L7 (Fig. 9E). Compared with the increases in synaptic strengths produced by two pairings alone $(n=6)$, the change in synaptic strength after overexpression of dn-classical in L7 on day $1(n=8)$ was significantly smaller on days 2,3 , and 5 . In contrast, overexpression of dn-SOL $(n=8)$ on day 1 failed to affect the expression of persistent associative LTF.

Overexpression of $\mathrm{dn}$-classical in the sensory neurons also blocked the expression of persistent associative LTF (Fig. 9F). Compared with the increases in synaptic strength produced by two pairings ( $n=6$ ), the change in synaptic strength after overexpression of dn-classical $(n=8)$ was significantly smaller on days 2,3 , and 5 . Overexpression of dn-SOL $(n=8)$ in the sensory neurons failed to affect persistent associative LTF. Thus, the same dominant-negative constructs that failed to interfere with the maintenance of persistent plasticity when overexpression begins on day 3 now impact the expression of persistent plasticity when overexpression begins on day 1 . Stimulus-dependent activation of specific calpain activities is required for the expression of different forms of persistent plasticity.

\section{Discussion}

We examined whether constitutively active PKCs, the PKMs, contribute to the maintenance of different forms of long-term plasticity starting $2 \mathrm{~d}$ after the stimuli that produced the plasticity. Our results suggest that repeated applications of 5-HT or pairing activity with a 5-HT application lead to the activation of specific calpains in the sensory neuron and in L7 that cleave PKCs into PKMs and contribute to the generation of cell-specific sets of PKMs. The constitutive presence of the PKMs in each neuron does not require the constitutive actions of the calpains. Specific PKM activities in each neuron contribute to the different forms of persistent plasticity. The results suggest that a timely stimulusdependent increase in a specific calpain activity and specific sets of PKM activities in the presynaptic and postsynaptic neurons are needed for maintaining different forms of long-term synaptic plasticity at the behaviorally relevant sensorimotor synapse of Aplysia (Table 1, Table 2).

\section{Cell-specific roles of PKMs in maintaining persistent LTF}

Different sets of PKMs in the presynaptic and postsynaptic neuron contribute to the maintenance of each form of LTF, and, in general, there is specificity in the actions of the dominant-negatives, suggesting a specific interaction in the sensory and motor neuron with each isoform of PKM. However, both dn-PKM Apl II and dn-PKM Apl III expressed in L7 reverse associative LTF, while both dn-PKM Apl II and dn-PKM Apl III expressed in the sensory neuron reverse nonassociative LTF. The similar effects of these two dominant-negatives may result because they share a similar scaffold/substrate and thus represent an example of nonisoform specificity of the dominantnegatives. Alternatively, it may result because both PKMs are inde- 

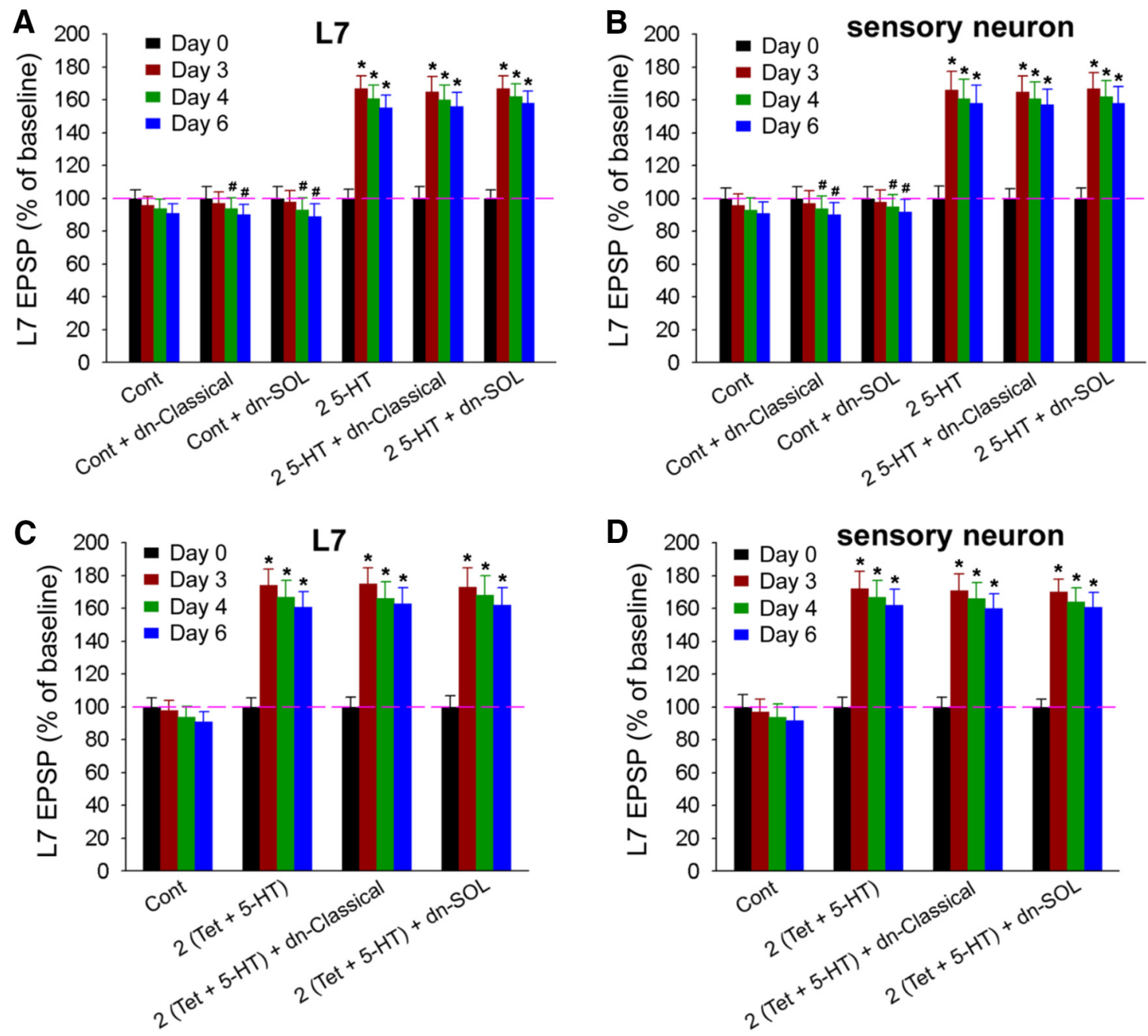

Figure 8. Classical or SOL calpain activity after day 3 is not required for maintaining persistent LTF. A, B, Summary of the changes in synaptic strength after control and 5-HT treatments that produced persistent nonassociative LTF with/without overexpression of dominant-negative constructs for classical or SOL calpains in L7 (A) or sensory neurons (B) on day 3. A two-factor ANOVA indicated a significant effect of treatment over time for $L 7\left(F_{(15,108)}=202.9 ; p<0.001\right)$ and for sensory neuron $\left(F_{(15,99)}=94.49 ; p<0.001\right)$. Individual comparisons indicated the following: $(1)$ overexpression of dn-classical or dn-SOL on day 3 after control treatment (Cont + dn-classical or Cont $+\mathrm{dn}-\mathrm{SOL}$ ) had no significant effect on synaptic baseline compared with control (\#) on day 4 $\left(F_{(5,36)}=0.0001\right.$ or 0.0002 , all $p>0.9$ for $L 7 ; F_{(5,33)}=0.0001$ or $0.005, p>0.8$ for sensory neuron) and day $6\left(F_{(5,36)}=0.002\right.$ or 0.007 , all $p>0.7$ for $L 7 ; F_{(5,33)}=0.0001$ or $0.002, p>0.8$ for sensory neuron); (2) 25 -HT produced a significant change in synaptic strength compared with control ( $\left.{ }^{*}\right)$ on days 3,4 , and $6\left(F_{(5,36)}=8.871,8.021\right.$, and 7.526 , all $p<0.01$ in $A ; F_{(5,33)}=5.804$, 5.315 , and 5.464, all $p<0.01$ in $B$ ); (3) 25-HT plus overexpression of either dn-classical or dn-SOL on day 3 had no significant effect on the changes in synaptic strength compared to that evoked by 25 -HT alone on day $4\left(F_{(5,36)}=0.004\right.$ or 0.002 , all $p>0.7$ for $\mathrm{L} 7 ; F_{(5,33)}=0.0001$ or 0.002 , all $p>0.8$ for sensory neuron $)$ and day $6\left(F_{(5,36)}=0.001\right.$ or 0.013 , all $p>0.6$ for $\mathrm{L} 7 ; F_{(5,33)}=0.001$ or 0.0001 , all $p>0.8$ for sensory neuron), and they remained significantly greater than those for control $\left(^{*}\right)$ on day $4\left(F_{(5,36)}=8.174\right.$ or 8.84 , all $p<0.01$ for $L 7 ; F_{(5,33)}=5.36$ or 5.496 , all $p<0.01$ for sensory neuron) and day $6\left(F_{(5,36)}=8.18\right.$ or 8.693 , all $p<0.01$ for $L 7 ; F_{(5,33)}=5.304$ or 5.464 , all $p<0.01$ for sensory neuron). C, $D$, Summary of the changes in synaptic strength after control and stimulation treatments that produce persistent associative LTF with and without overexpression of dominant-negative constructs for classical or SOL calpains in L7 (C) or sensory neurons $(\boldsymbol{D})$ on day 3. A two-factor ANOVA indicated a significant effect of treatment over time for $\operatorname{L7}\left(F_{(9,69)}=59.939 ; p<0.001\right)$ and for sensory neuron $\left(F_{(9,66)}=74.145 ; p<0.001\right)$. Individual comparisons indicated the following: (1) two pairings of stimuli $\left[2\right.$ (Tet +5 -HT)] produced significant changes in synaptic strength compared with control $(*)$ on days 3,4 , and $6\left(F_{(3,23)}=9.656,8.603\right.$ and 9.147 , all $p<0.01$ in $C ; F_{(3,22)}=10.216,9.845$ and 9.572 , all $p<0.01$ in $\left.D\right)$; (2) after two pairings of stimuli, overexpression of either dn-classical or dn-SOL on day 3 had no significant effect on the changes in synaptic strength compared with 2 (Tet $+5-\mathrm{HT})$ alone on day $4\left(F_{(3,23)}=0.001\right.$ or 0.002 , all $p>0.9$ for $\mathrm{L7} ; F_{(3,22)}=0.004$ or 0.018 , all $p>0.5$ for sensory neuron) and day $6\left(F_{(3,23)}=0.008\right.$ or 0.001 , all $p>0.7$ for $L 7 ; F_{(3,22)}=0.008$ or 0.001 , all $p>0.7$ for sensory neuron), and they remained significantly greater than those for control $(*)$ on day $4\left(F_{(3,23)}=8.436\right.$ or 8.874 , all $p<0.01$ for $\mathrm{L} 7 ; F_{(3,22)}=10.177$ or 9.735 , all $p<0.01$ for sensory neuron) and day $6\left(F_{(3,23)}=9.676\right.$ or 9.334 , all $p<0.01$ for $L 7 ; F_{(3,22)}=9.726$ or 10.148 , all $p<0.01$ for sensory neuron).

pendently important for plasticity. Although we cannot distinguish between these two possibilities directly, the finding that only dnPKM Apl II expressed in the sensory neuron reverses associative LTF argues against PKM Apl III and PKM Apl II competing for all forms of plasticity. While isoform-specific effects of the dn-PKMs were seen, we do not have an independent method to determine the efficacy of the dn-PKMs. Thus, we cannot rule out the possibility that the failure of a particular dominant-negative either in L7 or sensory neurons to reverse a particular form of plasticity was due to insufficient expression of the dn-PKM. If this were true, it would indicate that distinct forms of LTF had different thresholds for PKM activity since all dn-PKMs did reverse some form of plasticity at the level of expression obtained in a specific cell (Table 1).

Each PKM activity affects critical functions that are necessary for maintaining each form of plasticity, since blocking the activity of a single isoform (in either sensory neurons or L7) leads to the reversal of a specific form of long-term plasticity. In L7, these functions might include regulating the synthesis and distribution of molecules critical for different postsynaptic functions (Trudeau and Castellucci, 1995; Zhu et al., 1997; Sherff and Carew, 2002; 

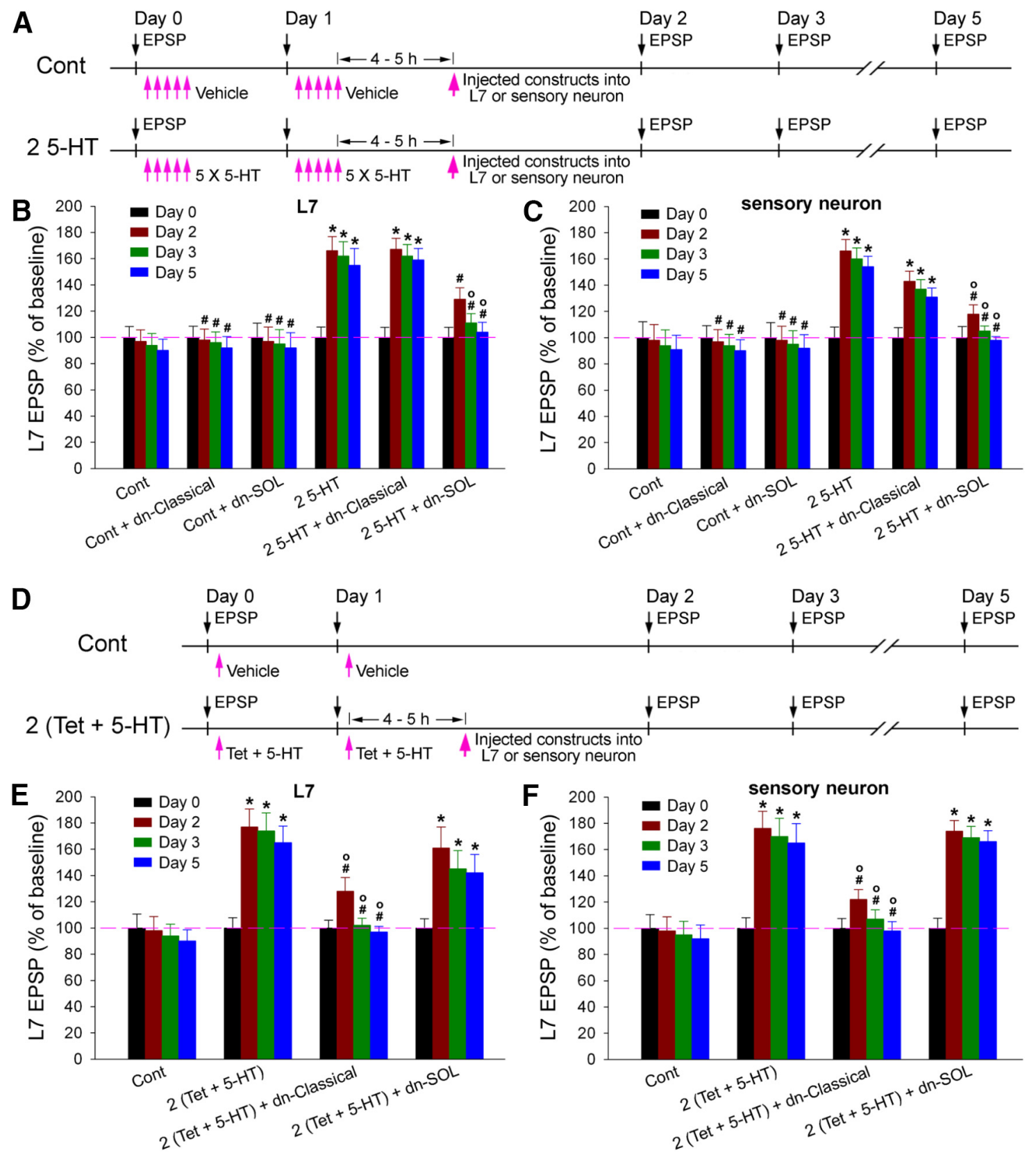

Figure 9. The SOL calpain isoform is required for the expression of persistent nonassociative LTF, while the classical calpain isoform is required for the expression of persistent associative LTF. $A$, The experimental protocol for examining the effects of overexpressing dominant-negative forms of calpain isoforms on the expression of persistent nonassociative LTF. Cultures were treated with two sets of 5-HT applications on days 0 and 1. Dominant-negative constructs of the different calpain isoforms were injected into $\mathrm{L} 7$ or sensory neuron $4-5 \mathrm{~h}$ after last application of 5 -HT on day 1 . EPSP amplitudes were tested before control or experimental treatments on day 0 and were retested on days 2,3 , and 5 . B, C, Summary of the change in the EPSP amplitudes for control and stimulated groups (25-HT) with and without overexpression of dn-SOL or dn-classical in L7 (B) or sensory neurons $(\boldsymbol{C})$ on day 1 . A two-factor ANOVA indicated a significant effect of treatment over time for $\mathrm{L} 7$ $\left(F_{(15,102)}=70.256 ; p<0.001\right)$ and for the sensory neurons $\left(F_{(15,102)}=25.562 ; p<0.001\right)$. Individual comparisons indicated the following: $(1)$ overexpression of dn-classical or dn-SOL in L7 on day 1 after control treatment had no significant effect on synaptic baseline compared with control (\#) on day $2\left(F_{(5,34)}=0.0003\right.$ or $0.0001 ;$ all $\left.p>0.9\right)$ and day $3\left(F_{(5,34)}=0.0004\right.$ or 0.0003 ; all $p>$ $0.9)$ and day $5\left(F_{(5,34)}=0.004\right.$ or 0.002 ; all $\left.p>0.7\right)$; (2) overexpression of dn-SOL or dn-classical in the sensory neurons on day 1 after control treatment had no significant effect on synaptic baseline compared with control (\#) on day $2\left(F_{(5,34)}=0.0005\right.$ or $0.0001 ;$ all $\left.p>0.9\right)$ and day $3\left(F_{(5,34)}=0.0001\right.$ or 0.002 ; all $\left.p>0.8\right)$ and day $5\left(F_{(5,34)}=0.0002\right.$ or 0.003 ; all $\left.p>0.8\right)$; (3) after stimulation to produce persistent nonassociative LTF (25-HT) and overexpression of dn-classical either in L7 or sensory neurons, the changes in synaptic strength remained significantly greater than control $(*)$ on days 2,3 , and $5\left(F_{(5,34)}=5.669,5.738\right.$, and 5.332 , all $p<0.01$ in $L 7 ; F_{(5,34)}=2.615,2.789$, and 2.854 , all $p<0.05$ in the sensory neuron); (4) after stimulation to produce persistent nonassociative LTF (25-HT) and overexpression of dn-SOL either in L7 or sensory neurons, the changes in synaptic strength were no longer significantly different from controls (\#) on days 2, 3, and $5\left(F_{(5,34)}=1.162,0.348\right.$, and 0.211 , all $p>0.05$ in $\mathrm{L} 7 ; F_{(5,34)}=0.527,0.205$, and 0.095 , all $p>0.1$ in the sensory neuron); (5) after stimulation to produce persistent nonassociative LTF ( $\left.25-\mathrm{HT}\right)$ and overexpression of dn-SOL either in L7 or sensory neuron, the changes in synaptic strength were significantly smaller $(\boldsymbol{o})$ than the change detected in 25 -HT alone on days 3 and 5 in $\mathrm{L} 7\left(F_{(5,34)}=3.169\right.$ and 2.922; all $p<0.05)$, and on days 2,3 , and 5 in the sensory neuron $\left(F_{(5,34)}=2.909,4.382\right.$, and 5.335 , all $\left.p<0.05\right)$. D. The experimental protocol for examining the effects of overexpressing dominant-negative forms of calpain isoforms on the expression of persistent associative LTF. Cultures were treated with pairings of tetanic stimulation in the sensory neuron plus a brief 5 -HT application on days 0 and 1 . Dominant-negative constructs of the different calpain isoforms were injected into $\mathrm{L} 7$ or sensory neuron $4-5 \mathrm{~h}$ after the last application of 5 -HT on day 1 . EPSP amplitudes were tested before control or experimental treatments on day 0 and retested on days 2,3 , and 5 . E, $\boldsymbol{F}$, Summary of the change in the EPSP amplitudes for control and stimulated groups [2 (Tet + 5 -HT)] followed by overexpression of dn-classical or dn-SOL in L7 ( $\boldsymbol{E})$ or sensory neurons $(\boldsymbol{F})$ on day 1 . A two-factor ANOVA indicated a significant effect of treatment over time for $\mathrm{L} 7\left(F_{(9,72)}=23.888\right.$; $p<0.001)$ and for the sensory neurons $\left(F_{(9,72)}=61.12 ; p<0.001\right)$. Individual comparisons indicated the following: $(1)$ after stimulation to produce (Figure legend continues.) 
Table 1. Overexpression of each dominant negative construct on day 3 in L7 or sensory neurons selectively affected persistent nonassociative LTF, persistent associative LTF, or synaptic baseline

\begin{tabular}{|c|c|c|c|c|c|c|}
\hline & PKM ApII & PKM Apl II & PKM ApI III & PKC Apl I & PKC Apl II & PKC Apl III \\
\hline L7 & Nonassociative LTF & Associative LTF & Associative LTF & NA & Synaptic baseline & Synaptic baseline \\
\hline Sensory neuron & NA & Nonassociative LTF-associative LTF & Nonassociative LTF & NA & Synaptic baseline & Synaptic baseline \\
\hline
\end{tabular}

The effect of dominant negative PKC Apl II or PKC Apl III on persistent LTF was not examined, since each significantly affected the synaptic baseline. Cell-specific PKM/PKC isoforms are required for the maintenance of different forms of persistent LTF and synaptic baseline. NA, none affected.

Table 2. Overexpression of each dominant-negative construct on day 1 had no effect on the synaptic baseline and a selective effect on a form of persistent LTF expressed on $\mathrm{d} 3$, and overexpression of the same dominant-negative constructs on day $3 \mathrm{had}$ no effect on any form of persistent LTF or the synaptic baseline

\begin{tabular}{llllll}
\hline & Injection on day 1 & & & \multicolumn{2}{l}{ Injection on day 3 } \\
\cline { 2 - 3 } & Classical calpain & SOL calpain & & Classical calpain & SOL calpain \\
\hline L7 & Associative LTF & Nonassociative LTF & NA & NA \\
Sensory neuron & Associative LTF & Nonassociative LTF & NA & NA
\end{tabular}

Different calpain isoforms are required for the expression of different forms of persistent LTF but not for the maintenance of different forms of persistent LTF or the synaptic baseline. NA, none affected.

Antonov et al., 2003; Cai et al., 2008; Hu et al., 2015) or of the retrograde signals acting on the presynaptic sensory neuron required for enhanced synaptic function (Zhu et al., 1995; Schacher et al., 2000; Hu et al., 2010; Choi et al., 2011).

Overexpression of dn-PKMs failed to alter the synaptic baseline, while some dn-PKCs did (Table 1). One explanation for this is that the dn-PKCs and dn-PKMs interfere with separate pathways. PKCs, through their regulatory domains, may interact with substrates and/or scaffolds that are involved in sustaining synaptic baseline (Haghighi et al., 2003; Seeburg and Sheng, 2008; Diering et al., 2014; Jalil et al., 2015), whereas PKMs do not. In contrast, dn-PKM Apl I expressed in L7 reversed nonassociative LTF, but dn-PKC Apl I did not. This could be due to dn-PKM Apl I interacting through domains that are masked in dn-PKC Apl I or to dn-PKC Apl I being sequestered by interactions through their regulatory domain and thus not competing for interactions with PKM Apl I. Alternatively, dn-PKM Apl I may be expressed at higher levels than dn-PKC Apl I, and higher levels of dn-PKC Apl I expression might reverse nonassociative LTF.

In the sensory neuron, PKM Apl II and PKM Apl III activities are required for maintaining nonassociative LTF, while only PKM Apl II activity is required for maintaining associative LTF. As in L7, the PKM activities in the sensory neuron are not required to maintain the synaptic baseline, while dn-PKC Apl II and dn-PKC Apl III expression decreased the synaptic baseline. PKC Apl I activity in the sensory neurons, but not PKM Apl I, is required to maintain a property characteristic of persistent associative LTF - the altered kinetics of HSD ( $\mathrm{Hu}$ and Schacher, 2015). The kinase activities in the presynaptic sensory neuron can

$\leftarrow$

(Figure legend continued.) persistent associative LTF [2 (Tet + 5-HT)] and overexpression of dn-classical either in $\mathrm{L} 7$ or sensory neurons, the changes in synaptic strength were no longer significantly different from control (\#) on days 2,3 , and $5\left(F_{(3,24)}=0.829,0.072\right.$, and 0.063 , all $p>0.1$ in $L 7 ; F_{(3,24)}=1.08,0.261$, and 0.063 , all $p>0.05$ in the sensory neuron), which were significantly smaller $(\boldsymbol{o})$ than the changes detected in 2 (Tet +5 -HT) alone $\left(F_{(3,24)}=2.277,6.968\right.$, and 6.736, all $p<0.05$ in $\mathrm{L} 7 ; F_{(3,24)}=5.19,6.857$, and 7.229, all $p<0.01$ in the sensory neuron); (2) after stimulation to produce persistent associative LTF [2 (Tet + 5-HT)] and overexpression of dn-SOL either in L7 or sensory neurons, the changes in synaptic strength remained significantly greater than those for control $\left({ }^{*}\right)$ on days 2,3 , and $5\left(F_{(3,24)}=3.727,3.456\right.$, and 3.923 , all $p<0.01$ in $\mathrm{L} 7 F_{(3,24)}=10.337,9.726$, and 8.652 , all $p<0.01$ in the sensory neuron), which were not significantly different from the changes detected in 2 (Tet +5 -HT) alone $\left(F_{(3,24)}=0.239,1.101\right.$, and 0.749 , all $p>0.05$ in $L 7 ; F_{(3,24)}=0.01,0.001$, and 0.0001 , all $p>$ 0.1 in the sensory neuron). impact gene and protein expression in their cell bodies (Impey et al., 1996; Martin et al., 1997b; Patterson et al., 2001; LimbäckStokin et al., 2004; Lee et al., 2007; Ma et al., 2015) and at distal synaptic sites (Hu et al., 2007, 2011; Wang et al., 2009; Wan et al., 2012; Hu and Schacher, 2015), or can influence orthograde signals such as the secretion of neuropeptides, whose downstream actions are to activate additional kinases in both presynaptic and postsynaptic compartments that are required for maintaining long-term synaptic plasticity (Hu et al., 2004, 2007, 2011; Kassabov et al., 2013; Kopec et al., 2015).

Although the general role of each PKM in the different synaptic partners may be similar (regulate the activity of transcription or translation factors or modify post-translational substrates in cell compartments), the overall function of a given PKM in each partner will affect different aspects of synaptic plasticity because of the different complement or expression levels of protein substrates and scaffolds in each cell type. With associative LTF, PKM Apl II in L7 may play a critical role in the formation and maintenance of new transmitter release sites (Hu et al., 2010), while PKM Apl III in L7 may regulate the distribution and concentration of postsynaptic glutamate receptors at release sites (Villareal et al., 2009; Migues et al., 2010). PKM Apl I may regulate the distribution and concentration of postsynaptic glutamate receptors at release sites with nonassociative LTF (Trudeau and Castellucci, 1995; Zhu et al., 1997). In the sensory neuron, PKM Apl II may regulate the secretion of neuropeptides such as sensorin critical for expression of both forms of LTF (Hu et al., 2006, 2007).

\section{Stimulus-dependent activation of specific calpain-mediated} cleavage of PKCs may regulate cell-specific PKMs

How does the nature of the stimuli determine which PKM activities in the sensory neuron and L7 maintain each form of persistent plasticity? Although calpain activity is required to generate the PKMs in Aplysia (Sutton et al., 2004; Bougie et al., 2009, 2012; Villareal et al., 2009; Farah et al., 2016), classical and SOL calpain activities $48 \mathrm{~h}$ after stimuli do not participate in maintaining the presence of the PKMs required for sustaining persistent LTF. However, there are additional calpains present in Aplysia (Farah et al., 2016), and it is possible that a distinct calpain isoform is required for the persistence of PKM activity. It is also possible that other intracellular proteases, such as caspases, could play a role. In addition, there may be other cellular mechanisms, such as ones that prevent degradation of PKMs that may be needed to preserve the constitutive presence of the PKMs in the absence of their continual formation through protein cleavage.

Activities of specific calpain isoforms at earlier time points after the stimuli are required for the expression of each form of persistent plasticity. Blocking SOL calpain activity in the sensory neuron or L7 soon after the stimuli blocked nonassociative LTF while blocking classical calpain activity in the sensory neuron or L7 soon after the stimuli blocked associative LTF. Thus, specific stimuli induce activation of cell-specific calpain activities both at earlier time points to mediate the cleavage of appropriate PKCs to 
produce intermediate forms of plasticity (Farah et al., 2016) and at later time points to generate the appropriate PKMs for maintaining nonassociative and associative LTF.

In summary, our results suggest that different stimuli activate different calpain isoforms that generate stimulus- and cell-specific sets of constitutively active PKMs. Different sets of constitutively active PKMs in the sensory neuron and L7 contribute to the maintenance of different forms of long-term plasticity. These results and those in the mouse hippocampus where several atypical PKCs can contribute to long-lasting long-term potentiation (Shema et al., 2011; Sacktor, 2012; Jalil et al., 2015; Tsokas et al., 2016) suggest that multiple constitutively active kinases (PKMs) in both presynaptic and postsynaptic neurons contribute to the maintenance of the long-term synaptic plasticity that underlies long-term memories.

\section{References}

Abel T, Nguyen PV, Barad M, Deuel TA, Kandel ER, Bourtchouladze R (1997) Genetic demonstration of a role for PKA in the late phase of LTP and in hippocampus-based long-term memory. Cell 88:615-626. CrossRef Medline

Abraham WC, Williams JM (2008) LTP maintenance and its protein synthesis-dependence. Neurobiol Learn Mem 89:260-268. CrossRef Medline

Abraham WC, Dragunow M, Tate WP (1991) The role of immediate early genes in the stabilization of long-term potentiation. Mol Neurobiol 5:297-314. CrossRef Medline

Abrams TW, Karl KA, Kandel ER (1991) Biochemical studies of stimulus convergence during classical conditioning in Aplysia: dual regulation of adenylate cyclase by $\mathrm{Ca}^{2+} /$ calmodulin and transmitter. J Neurosci 11 : 2655-2665. Medline

Alberini CM, Kandel ER (2014) The regulation of transcription in memory consolidation. Cold Spring Harb Perspect Biol 7:a021741. CrossRef Medline

Alberini CM, Ghirardi M, Metz R, Kandel ER (1994) C/EBP is an immediate-early gene required for the consolidation of long-term facilitation in Aplysia. Cell 76:1099-1114. CrossRef Medline

Antonov I, Antonova I, Kandel ER, Hawkins RD (2003) Activity-dependent presynaptic facilitation and hebbian LTP are both required and interact during classical conditioning in Aplysia. Neuron 37:135-147. CrossRef Medline

Bailey CH, Kandel ER, Harris KM (2015) Structural components of synaptic plasticity and memory consolidation. Cold Spring Harb Perspect Biol 7:a021758. CrossRef Medline

Basu J, Siegelbaum SA (2015) The corticohippocampal circuit, synaptic plasticity, and memory. Cold Spring Harb Perspect Biol 7:a021733. CrossRef Medline

Bougie JK, Lim T, Farah CA, Manjunath V, Nagakura I, Ferraro GB, Sossin WS (2009) The atypical protein kinase C in Aplysia can form a protein kinase M by cleavage. J Neurochem 109:1129-1143. CrossRef Medline

Bougie JK, Cai D, Hastings M, Farah CA, Chen S, Fan X, McCamphill PK, Glanzman DL, Sossin WS (2012) Serotonin-induced cleavage of the atypical protein kinase C Apl III in Aplysia. J Neurosci 32:14630-16440. CrossRef Medline

Buonomano DV, Byrne JH (1990) Long-term synaptic changes produced by a cellular analog of classical conditioning in Aplysia. Science 249:420423. CrossRef Medline

Cai D, Chen S, Glanzman DL (2008) Postsynaptic regulation of long-term facilitation in Aplysia. Curr Biol 18:920-925. CrossRef Medline

Cai D, Pearce K, Chen S, Glanzman DL (2011) Protein kinase M maintains long-term sensitization and long-term facilitation in Aplysia. J Neurosci 31:6421-6431. CrossRef Medline

Cameron AJ, Escribano C, Saurin AT, Kostelecky B, Parker PJ (2009) PKC maturation is promoted by nucleotide pocket occupation independently of intrinsic kinase activity. Nat Struct Mol Biol 16:624-630. CrossRef Medline

Caroni P, Donato F, Muller D (2012) Structural plasticity upon learning: regulation and functions. Nat Rev Neurosci 13:478-490. CrossRef Medline

Castellucci VF, Carew TJ, Kandel ER (1978) Cellular analysis of long-term habituation of the gill-withdrawal reflex of Aplysia californica. Science 202:1306-1308. CrossRef Medline

Chain DG, Casadio A, Schacher S, Hegde AN, Valbrun M, Yamamoto N, Goldberg AL, Bartsch D, Kandel ER, Schwartz JH (1999) Mechanisms for generating the autonomous cAMP-dependent protein kinase required for long-term facilitation in Aplysia. Neuron 22:147-156. CrossRef Medline

Choi YB, Li HL, Kassabov SR, Jin I, Puthanveettil SV, Karl KA, Lu Y, Kim JH, Bailey CH, Kandel ER (2011) Neurexin-neuroligin transynaptic interaction mediates learning-related synaptic remodeling and long-term facilitation in Aplysia. Neuron 70:468-481. CrossRef Medline

Cleary LJ, Lee WL, Byrne JH (1998) Cellular correlates of long-term sensitization in Aplysia. J Neurosci 18:5988-5998. Medline

Collingridge GL, Volianskis A, Bannister N, France G, Hanna L, Mercier M, Tidball P, Fang G, Irvine MW, Costa BM, Monaghan DT, Bortolotto ZA, Molnár E, Lodge D, Jane DE (2013) The NMDA receptor as a target for cognitive enhancement. Neuropharmacology 64:13-26. CrossRef Medline

Costa-Mattioli M, Sossin WS, Klann E, Sonenberg N (2009) Translational control of long-lasting synaptic plasticity and memory. Neuron 61:10-26. CrossRef

Diering GH, Gustina AS, Huganir RL (2014) PKA-GluAl couplilng via AKAP5 controls AMPA receptor phosphorylation and cell surface targeting during bidirection homeostatic plasticity. Neuron 84:790-805. CrossRef Medline

Duffy SN, Nguyen PV (2003) Postsynaptic application of a peptide inhibitor of cAMP-dependent protein kinase blocks expression of long-lasting synaptic potentiation in hippocampal neurons. J Neurosci 23:1142-1150. Medline

Farah CA, Hastings MH, Dunn TW, Gong K, Baker-Andresen D, Sossin WS (2016) A PKM generated by calpain cleavage of a classical PKC is required for activity-dependent intermediate-term facilitation in the presynaptic sensory neuron of Aplysia. Learn Mem 24:1-13. CrossRef Medline

Fiumara F, Rajasethupathy P, Antonov I, Kosmidis S, Sossin WS, Kandel ER (2015) MicroRNA-22 gates long-term heterosynaptic plasticity in Aplysia throough presynaptic regulation of CPEB and downstream targets. Cell Rep 11:1866-1875. CrossRef Medline

Frost WN, Castellucci VF, Hawkins RD, Kandel ER (1985) Monosynaptic connections made by the sensory neurons of the gill- and siphonwithdrawal reflex in Aplysia participate in the storage of long-erm memory for sensitization. Proc Natl Acad Sci U S A 82:8266-8269. CrossRef Medline

Haghighi AP, McCabe BD, Fetter RD, Palmer JE, Hom S, Goodman CS (2003) Retrograde control of synaptic transmission by postsynaptic CaMKII at the Drosophila neuromuscular junction. Neuron 39:255-267. CrossRef Medline

Hegde AN, Goldberg AL, Schwartz JH (1993) Regulatory subunits of cAMP-dependent protein kinase are degraded after conjugation to ubiquitin: a molecular mechanisms underlying long-term synaptic plasticity. Proc Natl Acad Sci U S A 90:7436-7440. CrossRef Medline

Hu JY, Schacher S (2014) Persistent long-term facilitation at an identified synapse becomes labile with activation of short-term heterosynaptic plasticity. J Neurosci 34:4776-4785. CrossRef Medline

Hu J, Schacher S (2015) Persistent associative plasticity at an identified synapse underlying classical conditioning becomes labile with short-term homosynaptic activation. J Neurosci 35:16159-16170. CrossRef Medline

Hu JY, Glickman L, Wu F, Schacher S (2004) Serotonin regulates the secretion and autocrine action of a neuropeptide to activate MAPK required for long-term facilitation in Aplysia. Neuron 43:373-385. CrossRef Medline

Hu JY, Wu F, Schacher S (2006) Two signaling pathways regulate the expression and secretion of a neuropeptide required for long-term facilitation in Aplysia. J Neurosci 26:1026-1035. CrossRef Medline

Hu JY, Chen Y, Schacher S (2007) Protein kinase C regulates synthesis and secretion of a neuropeptide required for activity-dependent long-term synaptic facilitation. J Neurosci 27:8927-8939. CrossRef Medline

Hu JY, Chen Y, Bougie JK, Sossin WS, Schacher S (2010) Aplysia cell adhesion molecule and a novel protein kinase $\mathrm{C}$ activity in the postsynaptic neuron are required for presynaptic growth and initial formation of specific synapses. J Neurosci 30:8353-8366. CrossRef Medline

Hu JY, Baussi O, Levine A, Chen Y, Schacher S (2011) Persistent long-term 
synaptic plasticity requires activation of a new signaling pathway by additional stimuli. J Neurosci 31:8841-8850. CrossRef Medline

Hu JY, Levine A, Sung YJ, Schacher S (2015) cJun and CREB2 in the postsynaptic neuron contribute to persistent long-term facilitation at a behaviorally relevant synapse. J Neurosci 35:386-395. CrossRef Medline

Huang YY, Martin KC, Kandel ER (2000) Both protein kinase A and mitogen-activated protein kinase are required in the amygdala for the macromolecular synthesis-dependent late phase of long-term potentiation. J Neurosci 20:6317-6325. Medline

Impey S, Mark M, Villacres EC, Poser S, Chavkin C, Storm DR (1996) Induction of CRE-mediated gene expression by stimuli that generate longlasting LTP in area CA1 of the hippocampus. Neuron 16:973-982. CrossRef Medline

Jalil SJ, Sacktor TC, Shouval HZ (2015) Atypical PKCs in memory maintenance: the roles of feedback and redundancy. Learn Mem 22:344-353. CrossRef Medline

Kaang BK (1996) Parameters influencing ectopic gene expression in Aplysia neurons. Neurosci Lett 221:29-32. CrossRef Medline

Kandel ER (2012) The molecular biology of memory: cAMP, PKA, CRE, CREB-1, CREB-2, and CPEB. Mol Brain 5:14. CrossRef Medline

Kassabov SR, Choi YB, Karl KA, Vishwasrao HD, Bailey CH, Kandel ER (2013) A single Aplysia neurotrophin mediates synaptic facilitation via differentially processed isoforms. Cell Rep 3:1213-1227. CrossRef Medline

Klann E, Chen SJ, Sweatt JD (1991) Persistent protein kinase activation in the maintenance phase of long-term potentiation. J Biol Chem 266: 24253-24256. Medline

Kopec AM, Philips GT, Carew TJ (2015) Distinct growth factor families are recruited in unique spatiotemporal domains during long-term memory formation in Aplysia. Neuron 86:1228-1239. CrossRef Medline

Kruger KE, Sossin WS, Sacktor TC, Bergold PJ, Beushausen S, Schwartz JH (1991) Cloning and characterization of calcium-dependent and calciumindependent PKCs expressed in Aplysia sensory neurons. J Neurosci 11: 2303-2313. Medline

Lanahan A, Worley P (1998) Immediate-early genes and synaptic function. Neurobiol Learn Mem 70:37-43. CrossRef Medline

Lee SH, Lim CS, Park H, Lee JA, Han JH, Kim H, Cheang YH, Lee SH, Lee YS, Ko HG, Jang DH, Miniaci MC, Bartsch D, Kim E, Bailey CH, Kandel ER, Kaang BK (2007) Nuclear translocation of CAM-associated protein activates transcription for long-term facilitation in Aplysia. Cell 129:801812. CrossRef Medline

Limbäck-Stokin K, Korzus E, Nagaoka-Yasuda R, Mayford M (2004) Nuclear calcium/calmodulin regulates memory consolidation. J Neurosci 24:10858-10867. CrossRef Medline

Lisman J (1994) The CaM kinase II hypothesis for the storage of synaptic memory. Trends Neurosci 17:406-412. CrossRef Medline

Liu J, Hu JY, Schacher S, Schwartz JH (2004) The two regulatory subunits of Aplysia cAMP-dependent protein kinase mediate distinct functions in producing synaptic plasticity. J Neurosci 24:2465-2474. CrossRef Medline

Lorenzetti FD, Baxter DA, Byrne JH (2008) Molecular mechanisms underlying a cellular analog of operant reward learning. Neuron 59:815-828. CrossRef Medline

Ma H, Li B, Tsien RW (2015) Distinct roles of multiple isoforms of CaMKII in signaling the nucleus. Biochim Biophys Acta 1853:19531957. CrossRef Medline

Malinow R, Madison DV, Tsien RW (1988) Persistent protein kinase activity underlying long-term potentiation. Nature 335:820-824. CrossRef Medline

Manseau F, Fan X, Hueftlein T, Sossin W, Castellucci VF (2001) Calciumindependent protein kinase C Apl II mediates the serotonin-induced facilitation at depressed Aplysia sensorimotor synapses. J Neurosci 21: 1247-1256. Medline

Maren S (2005) Synaptic mechanisms of associative memory in the amygdala. Neuron 47:783-786. CrossRef Medline

Marinesco S, Wickremasinghe N, Carew TJ (2006) Regulation of behavioral and synaptic plasticity by serotonin release within local modulatory fields in the CNS of Aplysia. J Neurosci 26:12682-12693. CrossRef Medline

Martin KC, Casadio A, Zhu H, Yaping E, Rose JC, Chen M, Bailey CH, Kandel ER (1997a) Synapse-specific, long-term facilitation of Aplysia sensory to motor synapses: a function for local protein synthesis in memory storage. Cell 91:927-938. CrossRef Medline

Martin KC, Michael D, Rose JC, Barad M, Casadio A, Zhu H, Kandel ER (1997b) MAP kinase translocates into the nucleus of the presynaptic cell and is required for long-term facilitation in Aplysia. Neuron 18:899-912. CrossRef Medline

Mayford M (2007) Protein kinase signaling in synaptic plasticity and memory. Curr Opin Neurobiol 17:313-317. CrossRef Medline

Migues PV, Hardt O, Wu DC, Gamache K, Sacktor TC, Wang YT, Nader K (2010) Nat Neurosci 13:630-634. CrossRef Medline

Montarolo PG, Goelet P, Castellucci VF, Morgan J, Kandel ER, Schacher S (1986) A critical period for macromolecular synthesis in long-term heterosynaptic facilitation in Aplysia. Science 234:1249-1254. CrossRef Medline

Nie T, McDonough CB, Huang T, Nguyen PV, Abel T (2007) Genetic disruption of protein kinase A anchoring reveals a role for compartmentalized kinase signaling in theta-burst long-term potentiation and spatial memory. J Neurosci 27:10278-10288. CrossRef Medline

Patterson SL, Pittenger C, Morozov A, Martin KC, Scanlin H, Drake C, Kandel ER (2001) Some forms of cAMP-mediated long-lasting potentiation are associated with release of BDNF and nuclear translocation of phosphor-MAP kinase. Neuron 32:123-140. CrossRef Medline

Purcell AL, Sharma SK, Bagnall MW, Sutton MA, Carew TJ (2003) Activation of a tyrosine kinase-MAPK cascade enhances the induction of longterm synaptic facilitation and long-term memory in Aplysia. Neuron 37: 473-484. CrossRef Medline

Redondo RL, Morris RG (2011) Making memories last: the synaptic tagging and capture hypothesis. Nat Rev Neurosci 12:17-30. CrossRef

Sacktor TC (2012) Memory maintenance by PKMzeta—an evolutionary perspective. Mol Brain 5:31. CrossRef Medline

Santini E, Huynh TN, Klann E (2014) Mechanisms of translation control underlying long-lasting synaptic plasticity and the consolidation of longterm memory. Prog Mol Biol Transl Sci 122:131-167. CrossRef Medline

Schacher S, Wu F, Sun ZY, Wang D (2000) Cell-specific changes in expression of mRNAs encoding splice variants of Aplysia cell adhesion molecule accompany long-term synaptic plasticity. J Neurobiol 45: 152-161. CrossRef Medline

Schafe GE, Nadel NV, Sullivan GM, Harris A, LeDoux JE (1999) Memory consolidation for contextual fear conditioning is dependent on protein synthesis, PKA and MAP kinase. Learn Mem 6:97-110. Medline

Seeburg DP, Sheng M (2008) Activity-induced Polo-like kinase 2 is required for homeostatic plasticity of hippocampal neurons during epileptiform activity. J Neurosci 28:6583-6591. CrossRef Medline

Shema R, Haramati S, Ron S, Hazvi S, Chen A, Sacktor TC, Dudai Y (2011) Enhancement of consolidated long-term memory by overexpression of protein kinase Mzeta in the neocortex. Science 331:1207-1210. CrossRef Medline

Sherff CM, Carew TJ (2002) Coincident induction of long-term facilitation at sensory-motor synapses in Aplysia: presynaptic and postsynaptic factors. Neurobiol Learn Mem 78:498-507. CrossRef Medline

Shobe JL, Zhao Y, Stough S, Ye X, Hsuan V, Martin KC, Carew TJ (2009) Temporal phases of activity-dependent plasticity and memory are mediated by compartmentalized routing of MAPK signaling in Aplysia sensory neurons. Neuron 61:113-125. CrossRef Medline

Sossin WS (2007) Isoform specificity of protein kinase Cs in synaptic plasticity. Learn Mem 14:236-246. Medline

Sossin WS, Sacktor TC, Schwartz JH (1994) Persistent activation of protein kinase C during the development of long-term facilitation in Aplysia. Learn Mem 1:189-202. Medline

Sutton MA, Schuman EM (2006) Dendritic protein synthesis, synaptic plasticity and memory. Cell 127:49-58. CrossRef Medline

Sutton MA, Bagnall MW, Sharma SK, Shobe J, Carew TJ (2004) Intermediate-term memory for site-specific sensitization in Aplysia is maintained by persistent activtation of protein kinase C. J Neurosci 24: 3600-3609. CrossRef Medline

Takeuchi T, Duszkiewicz AJ, Morris RG (2014) The synaptic plasticity and memory hypothesis: encoding, storage and persistence. Philos Trans R Soc Lond B Biol Sci 369:20130288. CrossRef Medline

Thiels E, Klann E (2001) Extracellular signal-regulated kinase, synaptic plasticity, and memory. Rev Neurosci 12:327-345. Medline

Thomas KL, Laroche S, Errington ML, Bliss TV, Hunt SP (1994) Spatial and temporal changes in signal transduction pathways during LTP. Neuron 13:737-745. CrossRef Medline

Trudeau LE, Castellucci VF (1995) Postsynaptic modifications in long-term 
facilitation in Aplysia: upregulation of excitatory amino acid receptors. J Neurosci 15:1275-1284. Medline

Tsokas P, Hsieh C, Yao Y, Lesburguères E, Wallace EJ, Tcherepanov A, Jothianandan D, Hartley BR, Pan L, Rivard B, Farese RV, Sajan MP, Bergold PJ, Hernández AI, Cottrell JE, Shouval HZ, Fenton AA, Sacktor TC (2016) Compensation for PKMzeta in long-term potentiation and spatial longterm memory in mutant mice. Elife 5:e14846. CrossRef

Veyrac A, Besnard A, Caboche J, Davis S, Laroche S (2014) The transcription factor Zif268/Egr1, brain plasticity, and memory. Prog Mol Biol Transl Sci 122:89-129. CrossRef Medline

Villareal G, Li Q, Cai D, Fink AE, Lim T, Bougie JK, Sossin WS, Glanzman DL (2009) Role of protein kinase $C$ in the induction and maintenance of serotonin-dependent enhancement of the glutamate response in isolated siphon motor neurons of Aplysia californica. J Neurosci 29:5100-5107. CrossRef Medline

Volk LJ, Bachman JL, Johnson R, Yu Y, Huganir RL (2013) PKM- $\zeta$ is not required for hippocampal synaptic plasticity, learning and memory. Nature 493:420-423. CrossRef Medline

Walters ET, Byrne JH (1983) Associative conditioning of singe sensory neurons suggests a cellular mechanism for learning. Science 219:405-408. CrossRef Medline

Walters ET, Carew TJ, Kandel ER (1981) Associative learning in Aplysia: cellular correlates supporting a conditioned fear hypothesis. Science 211: 504-506. CrossRef Medline

Wan Q, Jiang XY, Negroiu AM, Lu SG, McKay KS, Abrams TW (2012) Protein kinase $\mathrm{C}$ acts as a molecular detector of firing patterns to mediate sensory gating in Aplysia. Nat Neurosci 15:1144-1152. CrossRef Medline

Wang DO, Kim SM, Zhao Y, Hwang H, Miura SK, Sossin WS, Martin KC (2009) Synapse- and stimulus-specific local translation during longterm neuronal plasticity. Science 324:1536-1540. CrossRef Medline

Yang HW, Hu XD, Zhang HM, Xin WJ, Li MT, Zhang T, Zhou LJ, Liu XG (2004) Roles of CaMKII, PKA, and PKC in the induction and maintenance of LTP of C-fiber-evoked field potentials in rat spinal cord dorsal horn. J Neurophysiol 91:1122-1133. Medline

Zhao Y, Leal K, Abi-Farah C, Martin KC, Sossin WS, Klein M (2006) Isoform specificity of PKC translocation in living Aplysia sensory neurons and a role for $\mathrm{Ca}^{2+}$. dependent PKC APL I in the induction of intermediate-term facilitation. J Neurosci 26:8847-8856. CrossRef Medline

Zhu H, Wu F, Schacher S (1995) Changes in expression and distribution of Aplysia cell adhesion molecules can influence synapse formation and elimination in vitro. J Neurosci 15:4173-4183. Medline

Zhu H, Wu F, Schacher S (1997) Site-specific and sensory neurondependent increases in postsynaptic glutamate sensitivity accompany serotonin-induced long-term facilitation at Aplysia sensorimotor synapses. J Neurosci 17:4976-4986. Medline 